\title{
Manejo de recursos y coexistencia poblacional en la quebrada de Cobija durante la influencia inca
}

Iván Muñoz O. ${ }^{1}$

\begin{abstract}
RESUMEN
El estudio de los asentamientos Cobija-1 y Cobija-2 nos ha permitido discutir la interacción social que se llevó a cabo en la serranía de Arica entre los años 1400 DC a 1500 DC, según las fechas obtenidas por termoluminiscencia. Del análisis de la cerámica y la arquitectura se desprende que dichos asentamientos fueron edificados con el propósito de explotar agrícolamente y controlar los recursos hídricos de la quebrada de Cobija. Esta situación habría generado una coexistencia poblacional entre grupos nativos de la sierra y otro que llegó en representación del Estado inca, posiblemente de origen altiplánico.
\end{abstract}

Palabras claves: asentamientos - cerámica - Inca regional.

\begin{abstract}
Against the chronological background provided by $T L$ dated pottery, research undertaken in the sites of Cobija1 and Cobija-2 leads to consider the social interactions that occurred in the sierras of Arica between 1400 AD and 1500 AD. From the analysis of both ceramic remains and architecture, we consider that these settlements were built with the simultaneous purpose of controlling water resources, and exploiting agricultural produce in the valley of Cobija. We argue that this situation generated forms of population coexistence between native groups of the sierra, and people coming from the Andean high plains in representation of the Inca State.
\end{abstract}

Key words: settlements - ceramics - Regional Inca.

Recibido: febrero 2004. Manuscrito revisado aceptado: enero 2005.

\section{Introducción}

Los incas, como toda organización estatal, aprovecharon al máximo los recursos que les proporcionaban las tierras que eran integradas al Imperio. Los territorios de los Valles Occidentales tuvieron significativa importancia ya que proporcio-

\footnotetext{
1 Departamento de Arqueología y Museología, Universidad de Tarapacá. Casilla 6D, Arica, CHILE. Email: imunoz@uta.cl
}

naron recursos agrícolas y costeros. Sin embargo, son varias las hipótesis que se han planteado respecto a este dominio: Raffino plantea que los incas no construyeron grandes poblaciones en los Andes Meridionales (Collasuyu), sino que se "apropiaron de las poblaciones preexistentes" (1996: 71). Hyslop (1992) señala que el eje articulador que anexó todos los territorios conquistados estuvo dado por el Qhapaqñan que se desplaza tanto por la sierra como por la costa. No obstante, también integraron a esta red caminos preexistentes construyendo cada ciertos tramos recintos administrativos donde se ejercía el poder del Estado. Morris (1981) añade que los incas construyeron estos centros administrativos en lugares donde por lo general no existían edificaciones locales. Sobre el carácter de la dominación al sur del Imperio, Williams y D'altroy (1998: 170) señalan que si bien ésta fue menos intensa que en la zona nuclear o central del Perú no fue "... marginal, ajustando su gobierno a las características ambientales y sociopolíticas de cada región”.

El control indirecto habría sido la estrategia adoptada por los incas para dominar la región centro sur desplazando a los colonos del altiplano. Esta estrategia, según Llagostera (1976), Rice y colaboradores (1990) y Muñoz (1998), al parecer no fue tan compleja, ya que estos valles habían sido colonizados a través de enclaves, por las poblaciones de habla aymara, como Lupacas, Pacajes y Carangas, aproximadamente 300 años antes que llegaran los incas. Esta estrategia difiere de otras utilizadas por el Tawantinsuyu en la cual se removió la población local, y, en otros casos, se trasladaron emigrantes cusqueños (Querejazu 1989).

En cuanto a las relaciones que se establecieron entre el poder estatal y las etnias dominadas se ha planteado (D'Altroy y Bishop 1990; D'altroy 1992) que estas pudieron haber sido unidireccionales, asimétricas. Para Mulvany (2003: 179) esta interacción "implicó la búsqueda de equilibrio a través de la concertación". Al margen de estos planteamientos, Rivera señala que: 
"el área de Arica y Tarapacá estuvo directamente incorporada al Imperio inca, esto es, al sistema del Estado centralizado, permitiendo continuar con el modelo de complementariedad económica, modelo que se había establecido en la zona con anterioridad a los incas" (2002: 238).

Llagostera (1976), Cavagnaro (1986), Pärssinen (1992) y Muñoz (1998), entre otros, señalan que la ocupación incaica, en los valles desérticos de los extremos norte de Chile y sur de Perú, se habría producido en el siglo XV como consecuencia de las alianzas entre los incas y los reinos aymaras (collas), lo que permitió alcanzar el control político del altiplano y, por ende, de los valles costeros del Pacífico (Tambo, Moquegua, Sama, Ilabaya, Lluta, Azapa) donde estas poblaciones altiplánicas mantenían territorios agrícolas.

Algunos antecedentes de esta ocupación están en los asentamientos Lupacas en Torata. Diez de San Miguel (1964 [1567]) señala que indios Pacajes tenían asiento en Moquegua con el propósito de recolectar el guano como fertilizante y producir maíz, cuyos excedentes eran enviados a los centros del Imperio (Julien 1983). Según Rice y colaboradores (1990) estas poblaciones habrían coexistido con los yungas costeros nativos; sin embargo, estos grupos, al margen de la incorporación que hicieran de diversos elementos de la cultura material y tecnología, mantuvieron su forma de vida ancestral vinculada a la tradición de pescadores prehispánicos. Según Muñoz (1989), es posible que estos pescadores hayan perdurado en pequeños enclaves incluso hasta después del contacto andino-europeo.

Respecto al control político de los Valles Occidentales, existen diversas teorías planteadas por autores como Murra (1975), Hidalgo y Focacci (1986), Muñoz (1989), Silva (1992-1993), Santoro (1995) y Rivera (2002), quienes coinciden en que el aspecto más relevante de este tema radica en la relación que las poblaciones yungas mantuvieron con las altiplánicas. Según Murra (1975), este nexo habría existido durante la época preincaica bajo un sistema de control vertical de los Valles Occidentales ejercido por poblaciones provenientes de las tierras altas.

Para esta misma época en estos valles, Rostworowsky (1986) sugiere la existencia de un territorio conocido como "Colesuyu", donde se habría forjado una identidad cultural conformada por pescadores llamados "camanchacas" o "cavanchas", los que pudieron haber hablado el dialecto Coli, y agricultores que se hacían llamar "coles". Según esta autora, habrían mantenido una activa interacción con las poblaciones altiplánicas, especialmente en las cabeceras de los valles, intercambiando productos y bienes. Propone que tal interacción se origina por "la carencia de un centro de poder fuerte en los llanos, lo que hizo que, durante el Intermedio Tardío, los yungas estuvieran supeditados al dominio de los serranos del altiplano" (1986: 128).

La arqueología ha presentado evidencias que tienden a avalar ambas propuestas etnohistóricas, la de un modelo de control vertical ejercido por poblaciones altiplánicas (Hidalgo y Focacci 1986) y la de una población yunga local controlando los Valles Occidentales (Muñoz et al. 1987a, 1987b; Muñoz y Chacama 1988, 1995). Respecto de esta última propuesta, el territorio que se señala como Colesuyu ha sido ubicado en un espacio geográfico donde se hayan y distribuyen los elementos culturales que caracterizaron a la Cultura Arica (1000-1400 DC). Silva, al analizar los antecedentes proporcionados por Muñoz y Chacama (1993) respecto de las poblaciones nativas de los Valles Occidentales anteriores a los incas, señala que "es importante tener en cuenta las variaciones regionales y las condiciones previas de los establecimientos preincas en el norte de Chile cuando se trata de explicar la naturaleza de la expansión" (1992-1993: 90), más aún cuando se han detectado territorios que representaban unidades geopolíticas anteriores a los incas, como el Colesuyu.

Sobre los valles de Arica, Hidalgo y Focacci (1986) plantean para el siglo XVI la presencia de gente perteneciente a comunidades de Tarapacá, Tacna, Ilo, Pacajes, Yungas y Carangas, además de otras poblaciones asentadas en el valle de Lluta que decían ser Lupacas. Todas ellas habrían coexistido con el propósito de explotar las tierras agrícolas y los recursos marinos. Sobre la continuidad de la población local, es posible que ésta haya coexistido con otras influenciadas por los incas en la región durante la Fase Gentilar de la Cultura Arica (Hidalgo 1996). Esta hipótesis ha sido comprobada en varios asentamientos arqueológicos, tanto en Tacna como en Lluta y costa de Arica, en los cuales se han identificado contextos 
de dicha fase asociados a rasgos incaicos (Hidalgo y Focacci 1986; Muñoz 1998).

No obstante el esquema planteado, existen algunas interrogantes que merecen ser expuestas. Una de ellas apunta a que, si bien existen evidencias de una contemporaneidad de las culturas locales con la influencia incaica en la zona, el impacto producido en éstas debió ser considerable. Visualmente es posible percibir una pérdida de la riqueza iconográfica tanto en la textilería como en la alfarería preinca, situación que a nuestro entender refleja una nueva estructura política-ideológica, la inca, y cuyos mecanismos de interacción con las culturas locales no están aún plenamente esclarecidos.

\section{Evidencias arqueológicas relacionadas al Período Tardío}

Los valles de los extremos sur peruano y norte de Chile fueron ocupados por las poblaciones preincaicas e incas en distintas cotas con el propósito de explotar los recursos que el medio les ofrecía. En los valles, los agricultores herederos de la tradición cultural Tiwanaku dieron un fuerte impulso a las actividades agrarias, las que se manifiestan en el desarrollo de las técnicas de irrigación (canales) y del cultivo en terrazas, cubriendo extensas zonas y vinculando poblados distantes entre sí. Por tal razón, el manejo del agua fue el centro de atención de estas poblaciones, y la ubicación de la mayor parte de sus aldeas en el sector medio y cabeceras de valles fue, en gran medida, motivada por tal preocupación. Sin embargo, el control político de la región fue también un elemento gravitante en la organización de estas poblaciones, lo que las hizo conformar una identidad étnica conocida arqueológicamente como Cultura Arica (Schiappacasse et al. 1989).

\section{El extremo sur peruano}

En el valle de Moquegua, algunos asentamientos ocupados a partir del Período Intermedio Tardío como Estuquiña, San Antonio y Tumilaca-Molino, proporcionan también información arqueológica tardía. Se trata de poblados ubicados estratégicamente en la cima de cerros, con muros exteriores defensivos y estructuras domésticas formadas por aterrazamientos y muros de piedra situados alrededor de plazas. Un asentamiento con particularidades distintas a las mencionadas es
Llaral, el cual no posee atributos defensivos, sino más de 100 terrazas habitacionales dispuestas en forma de anfiteatro. Alrededor de estas estructuras se hallan dos cementerios y una plaza. La cerámica incluye vasijas de los estilos Chiribaya, San Miguel y Gentilar, de las poblaciones locales del Intermedio Tardío. Según Rice y colaboradores (1990), los asentamientos incas en el valle de Moquegua se localizan en terrenos accesibles, no fortificados, como Camatra y Tambolomo, con más de 20 estructuras. En ambos sitios se hallaron estilos cerámicos relacionados a poblaciones altiplánicas como Sillustani Policromo y Sillustani Negro sobre Rojo.

Torata es otro asentamiento inca más extenso que alcanza 7 ha. Se emplaza en la cima de un cerro circundado por una gran terracería agrícola. Torata Alta, está compuesta por habitaciones, patios y calles distribuidas en un plano inclinado, además de pozos de almacenajes. Según Rice y colaboradores (1990), este asentamiento pudo representar la comunidad inca de Cochuna, constituyéndose en un centro administrativo de gran importancia en la cuenca del Osmore.

Un poblado relacionado a las fases Estuquiña-Inca e Inca en el valle de Otora (cuenca del Osmore), es Porobaya. Según Stanish (1990) Porobaya-1, 3 y 6 corresponden a unidades políticas independientes engranadas en un intercambio interzonal intensivo. En estos asentamientos existe una marcada influencia colla de la cuenca del Titicaca, y se manifiestan las primeras evidencias incaicas en el valle. A su vez, Porobaya-11, 13 y 15, son asentamientos cuyas economías políticas están marcadas por la administración imperial, con especial influencia de los Lupacas. Es en este período cuando se comienza a construir el complejo habitacional de Torata, de influencia Inca-Lupaca, cuya alfarería típica incluye, además, los estilos Chucuito y Sillustani.

En el valle de Ilo, en el sitio Algarrobal, se han localizado antiguos sistemas agrícolas y bases de estructuras habitacionales hechas de caña y de madera, vinculadas a poblaciones del Intermedio Tardío. Se suman los hallazgos de los cementerios de Chiribaya Alta, Carahuas, El Algarrobal, El Algodonal, El Higueral, El Mono, Loreto Viejo y Parral, que se relacionan a poblaciones costeras preincaicas y a la Cultura Chiribaya. Algunos de estos grupos perduraron hasta la época 
inca en un contexto de coexistencia poblacional, lo cual implica que los incas habrían respetado ciertos iconos que identificaron a estas poblaciones costeras.

El valle del Caplina en Tacna fue anexado al territorio inca, según Gordillo (1996), durante el gobierno de Tupac Yupanqui, aproximadamente en 1475. Algunos de los aportes incas, reconoce Gordillo, es la introducción de un nuevo sistema administrativo evidenciado en construcciones que obedecieron a un modelo central (tambos) y mejoramiento de la red vial. La cerámica tiende a mostrar nuevas formas y decoración, volviéndose más funcional. Algunos asentamientos del Período Inca en el extremo sur peruano son Peañas, Pachía, Challada y Pallagua en el Caplina; Sama la Antigua, Pampa Julia, Yalata, Kanamarca, Capanique, Huankarani, en los valles de Sama; Pocoma en Lucumba; Punta Meca e Ite en el litoral, y Palca en la zona altoandina. Para el valle de Tacna, Gordillo (1996) señala que existieron tres elementos que caracterizaron las conductas de las poblaciones yungas: uso racional del agua para la actividad agrícola, intensa actividad comercial manifestada por el tráfico de caravanas y el profundo sentido mágico-religioso manifestado en diferentes expresiones simbólicas de la cultura material (textiles, cerámica, petroglifos, geoglifos, entre otros).

Un análisis más detallado sobre la ocupación inca en el valle de Tacna, desde el cementerio de Peañas, es realizado por Gordillo y García (1989), quienes detectan cerámica de estilo ChuquibambaInca con formas de jarra. Esta es la alfarería más diagnóstica de la ocupación inca en el valle de Tacna. En tumbas registraron platos decorados con representaciones ornitomorfas y aríbalos Cusco Policromo, además de un plato decorado con llamas estilizadas, emparentadas con el estilo Saxamar de Arica (Dauelsberg 1961) o Inca Pacajes del altiplano meridional (Rydén 1947). Entre las ofrendas hubo vasos de madera, cestería, "coquitos", y productos alimenticios tales como maíz, porotos, ají, achira, chañar, calabazas y frutos de molle. Otros estilos cerámicos de tradición costera que aparecen en las tumbas de Peañas, lo constituyen Pocoma y Gentilar de la Cultura Arica. Los desarrollos locales de los valles interandinos están representados por el estilo Sitajara, de manufactura simple, con alisado regular, y formas de cuencos con pequeños protúberos. En Peañas se observan distintos tipos de entierros ocupando un mismo espacio, lo cual podría sustentar una hipótesis de convivencia multiétnica en el valle de Caplina (Gordillo 1996).

Respecto de la ocupación inca en la precordillera de Tacna, ésta puede observarse en los poblados de Capinaque y Pukara, en el valle de Sitajara. Capinaque está formado por recintos de planta rectangular con muros de una y doble hilera de piedras, algunos usando argamasa. En este poblado se haya un tambo compuesto por tres recintos rectangulares, en cuya superficie se han hallado fragmentos de cerámica de los estilos Sitajara, Pocoma e Inca, este último representado por Chucuito Policromo, Cusco Policromo-B, Saxamar, Chucuito Negro sobre Rojo y Kollau. Por otra parte, Pukara es un asentamiento de carácter defensivo, con muros de contención aterrazados. Las estructuras que se edificaron sobre estos aterrazamientos son de planta rectangular, algunas de las cuales presentan accesos. Asociado a este espacio hay un sector de enterramiento conformado por chullpa y tumbas cavadas en el piso. Entre la cerámica local tiene mayor representación aquella de pasta gris y gris-rojiza, junto a cerámica costera de estilo Pocoma, y Chilpe del Desarrollo Regional altiplánico. Para Gordillo (1996), las poblaciones locales del valle serían de origen precordillerano, representadas por el estilo Sitajara, las que habrían coexistido con aquellas de la costa de Arica y con las altiplánicas, representadas por las variantes negro sobre rojo a las cuales se asocia posteriormente el Inka.

En el río de Sama, Trimborn (1975) fechó varios asentamientos con cerámica de los estilos costeros San Miguel, Pocoma y Gentilar cuyo rango cronológico va desde 1090 DC hasta 1560 DC, que representarían poblaciones costeras que tuvieron una larga vigencia en el tiempo. Lo interesante de estos asentamientos es que presentan un patrón arquitectónico habitacional que no cambia en el tiempo, lo cual sugiere que la influencia incaica no modificó el estilo arquitectónico de los poblados indígenas locales, el que sobrevive incluso a la llegada de los europeos.

\section{El extremo norte de Chile}

Los valles costeros de Lluta y Azapa corresponden a dos hoyas hidrográficas cuyas cabeceras alcanzan los 2600 a 3000 m.snm, distribuyéndose 
en estos espacios una gran cantidad de sitios preincaicos e incas. En el valle de Lluta se encuentran Mullune, Molino, Vila-Vila, Molle Pampa, Rosario, Huaylacan, Chacalluta y Macarena, estos dos últimos emplazados en la desembocadura. Los poblados presentan una planificación sectorizada en donde destacan los lugares de enterramiento caracterizados por fosas ampollares y tubulares, y áreas residenciales construidas con muros de piedra y caña. Las construcciones se localizan en lugares de amplio dominio visual, en terrazas inmediatas a la caja del río.

Un análisis de las relaciones y ocupación del espacio por parte de las poblaciones prehispánicas tardías asentadas en el valle de Lluta, ha sido realizado por Santoro (1995), quien plantea la interacción entre los grupos étnicos macrorregionales de la Subárea Circumtiticaca y los grupos microrregionales de origen valle-costero. Santoro ha podido establecer que entre estos dos grupos se dio una interrelación regional directa, diferente a lo que habría ocurrido en otros valles costeros como Azapa, en donde la penetración altiplánica desde la Subárea Circumtiticaca habría sido menos representativa y más tardía.

Por su parte, el valle de Azapa registra varios asentamientos. Desde el sector de Livilcar hacia la costa encontramos los poblados de Pubrisa, Chamarcusiña, Quebrada del Diablo, San Miguel (AZ-9 y AZ-10), Alto Ramírez (AZ-15), Playa Miller (PIM-3, PIM-4, PIM-5 y PIM-6), entre otros, los cuales incluyen cementerios con tumbas de tipo ampollar y tubular (Dauelsberg 1961; Espoueys et al. 1995; Muñoz 1996). Las residencias se construyeron con paredes de caña sobre peñones altos ubicados en lugares estratégicos desde donde se desarrollaron actividades agropesqueras. Es importante señalar que la cuenca del río San José se conecta directamente con el área de Belén en la serranía, constituyéndose en un rebalse que desemboca en el Pacífico. Esto propició una constante movilidad de poblaciones serranas y costeras, evidenciada por los numerosos senderos que cruzan la sierra y el valle, así como por el arte rupestre, que en sus diferentes manifestaciones se asocia directa o indirectamente a ellos.

Ahora bien, respecto de la ocupación de este valle por parte de los incas, hemos visto dos modalidades: a) grupos incas altiplánicos asociados a poblaciones locales (Hidalgo y Focacci 1986); y b) grupos incas altiplánicos tipo "mitimaes" no asociados con poblaciones locales (Santoro y Muñoz 1981). Ambas modalidades habrían estado orientadas a explotar los valles costeros del Pacífico, a través de cultivos como el maíz, papa, frutas y hortalizas (Alvarez 1991). Según este autor, los incas habrían desarrollado mecanismos para usar en forma diferenciada el espacio económico, de modo que en las aguas saladas del valle de Lluta se cultivó preferentemente maíz; en cambio, en las aguas dulces del valle de Azapa se prefirieron hortalizas y frutales. Esta percepción del uso diferenciado del espacio tuvo una connotación política y social, puesto que el Estado inca habría construido algunos centros administrativos para controlar la producción, uno de los cuales habría sido el asentamiento de Molle Pampa en el valle de Lluta (Santoro 1995) y AZ-15 en el valle de Azapa (Santoro y Muñoz 1981).

En el tramo inferior del río Camarones los poblados están representados por la Hacienda de Camarones, Chiza, Cuya, poblado de Punta Norte, Terraza Sur y Camarones-18, los cuales se emplazan en lugares de amplio dominio visual. El material de construcción fue la quincha y pircas de piedra, algunas de doble hilada. Por otra parte, los cementerios se construyeron en las laderas y terrazas cercanas a la desembocadura. Quienes ocuparon estos asentamientos fueron agricultores y pescadores; logrando estos últimos una alta especialización tecnológica como lo demuestran los contextos arqueológicos (Muñoz 1989). Aquí encontramos una marcada interacción entre poblaciones costeras y agricultores de valles serranos, generada como consecuencia de la necesidad de complementar ambos tipos de producciones.

El arribo permanente de poblaciones procedentes de los valles de Timar, Codpa y Esquiña hacia la desembocadura de Camarones hasta mediados del siglo XX, en busca de guano y productos marítimos, explican un proceso natural de integración económica y social cuyos orígenes se remontan a la época prehispánica tardía. Para avalar esta idea, señalemos la presencia de numerosos senderos y sitios con arte rupestre interconectados en muchos casos, a los poblados anteriormente mencionados.

La influencia incaica, en la desembocadura de Camarones, no estuvo marcada por elementos significativos de tradición cusqueña, sino, más bien, 
por estilos de la Subárea Circumtiticaca, como es posible determinar a través de los poblados de Punta Norte y Terraza Sur (Muñoz 1989). Con los incas se intensificaron las relaciones de intercambio, lo que se manifiesta por un mayor número de senderos en la quebrada y en las laderas de cerro. Esto habría ayudado a que en la costa se concentrara un mayor número de camélidos, evidenciado por abundantes restos de huesos, coprolitos y cueros, y a que se aumentara la explotación de los recursos agrícolas y marítimos, y del guano; además de un auge en tecnologías cerámicas y de metales, en especial de cobre, generándose un aumento de la población, la que centró sus esfuerzos en el mantenimiento de una producción y tecnologías para la sustentación del Estado.

\section{Area de estudio}

La quebrada de Cobija se ubica en la sierra de Huaylillas, I Región de Chile, a 2850 m.snm (Figura 1). En ella se emplazan los asentamientos Cobija-1 y Cobija-2, los que, según la arquitectura y la cerámica de superficie, habrían sido construidos durante el Período Tardío. A partir de estas materialidades es posible analizar las estrategias organizativas establecidas por las poblaciones que ocuparon ambos asentamientos, los que habrían tenido un rol importante en el control de la sierra de Arica, por parte del Estado inca.

Cobija-1 se emplaza en el margen norte del río homónimo ocupando las cotas superiores del cerro Tangani (UTM: 438207 E / 7928143 N, 3500 m.snm) (Figura 2). Específicamente, la geomorfología donde se asienta la ocupación está dada por dos quebradillas, afluentes temporales del cauce principal. Una orientación específica hacia el este lo determina el cerro Márquez, mientras que al oeste se ubica la estancia de Buenavista, en el margen sur del río, para finalmente llegar al pueblo de Cobija. Por el norte dominan cadenas de cerros al igual que por el sur.

El asentamiento Cobija-2 ocupó los faldeos bajos de la ladera sur de la quebrada de Cobija, distante $1 \mathrm{~km}$ al oeste del actual pueblo de Cobija (UTM 438320 E / 7928065 N).

De la excavaciones llevadas a cabo en 10 recintos -cinco en Cobija-1 y cinco en Cobija-2-, se obtuvo escaso material orgánico (225 gr), entre el que se cuentan huesos de aves, roedores y camélidos; restos de vegetales como pacae, papa, mazorcas de maíz, semillas de molle, ichu, queñua, quinoa, carbón y espinas de cactácea. También fueron identificados, aunque en una mínima cantidad, restos de espinas de pescados, conchas de moluscos, algas y camarones, además de lana y cuero de vicuña y llama. Finalmente se encontraron costrones de sal en la base del estrato ocupacional.

\section{Metodología}

La metodología utilizada para describir los asentamientos fue la siguiente: a) identificación de las áreas de actividad en el contexto económico (almacenaje, cultivos y corrales), ritual (funerario), doméstico y de convergencia; b) uso del espacio de la quebrada, lo que implica su cercanía a los recursos hídricos y las bondades del suelo agrícola; ubicación estratégica en altura como objetivo ceremonial y de control del espacio; c) identificación de estructuras y probable función. Este análisis se determinó en base al reconocimiento total del asentamiento, evidencias de áreas de actividad en la superficie de los recintos, e información proporcionada por las excavaciones y pozos de sondeo. Además se consideró el análisis de rasgos cuantificados en base a los levantamientos topográficos; d) características constructivas de los recintos con el propósito de establecer patrones arquitectónicos locales y con influencia externa (Muñoz et al. 1997); e) distribución de redes viales internas y externas del poblado con el propósito de establecer mecanismos de movilidad e intercambio.

\section{Modelo de asentamiento de Cobija-1}

El asentamiento está conformado por estructuras distribuidas de forma homogénea. Se hallan muy bien conservadas, lo que permite identificar fácilmente su estilo arquitectónico. Poseen planta oval, muros de doble hilada de piedras con sedimentación como relleno. Los cimientos están constituidos por el acuñamiento de grandes bloques sobre los cuales el pircado alcanza una altura promedio de $1.5 \mathrm{~m}$ y diámetros de $6 \mathrm{~m}$ a $5 \mathrm{~m}$, no registrándose mampostería. Los accesos tienden a estar orientados hacia el suroeste. Grandes jambas de piedra demarcan pasillos con un promedio de ancho de $0.5 \mathrm{~m}$. Exteriormente, la edificación de los muros se orienta hacia la pendiente. Los muros 


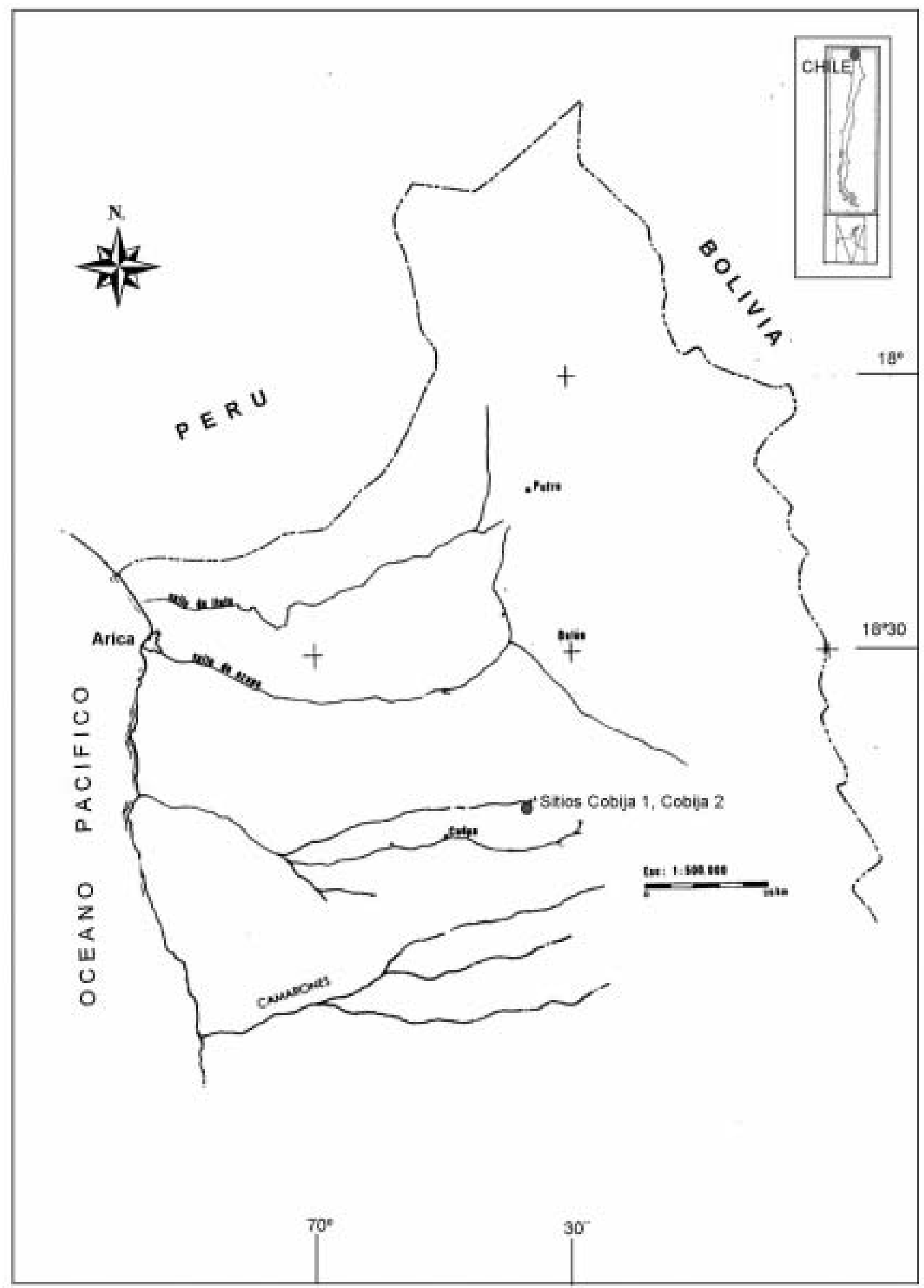

Figura 1. Mapa que muestra la ubicación de los sitios Cobija-1 y Cobija-2, en el extremo norte de Chile. 


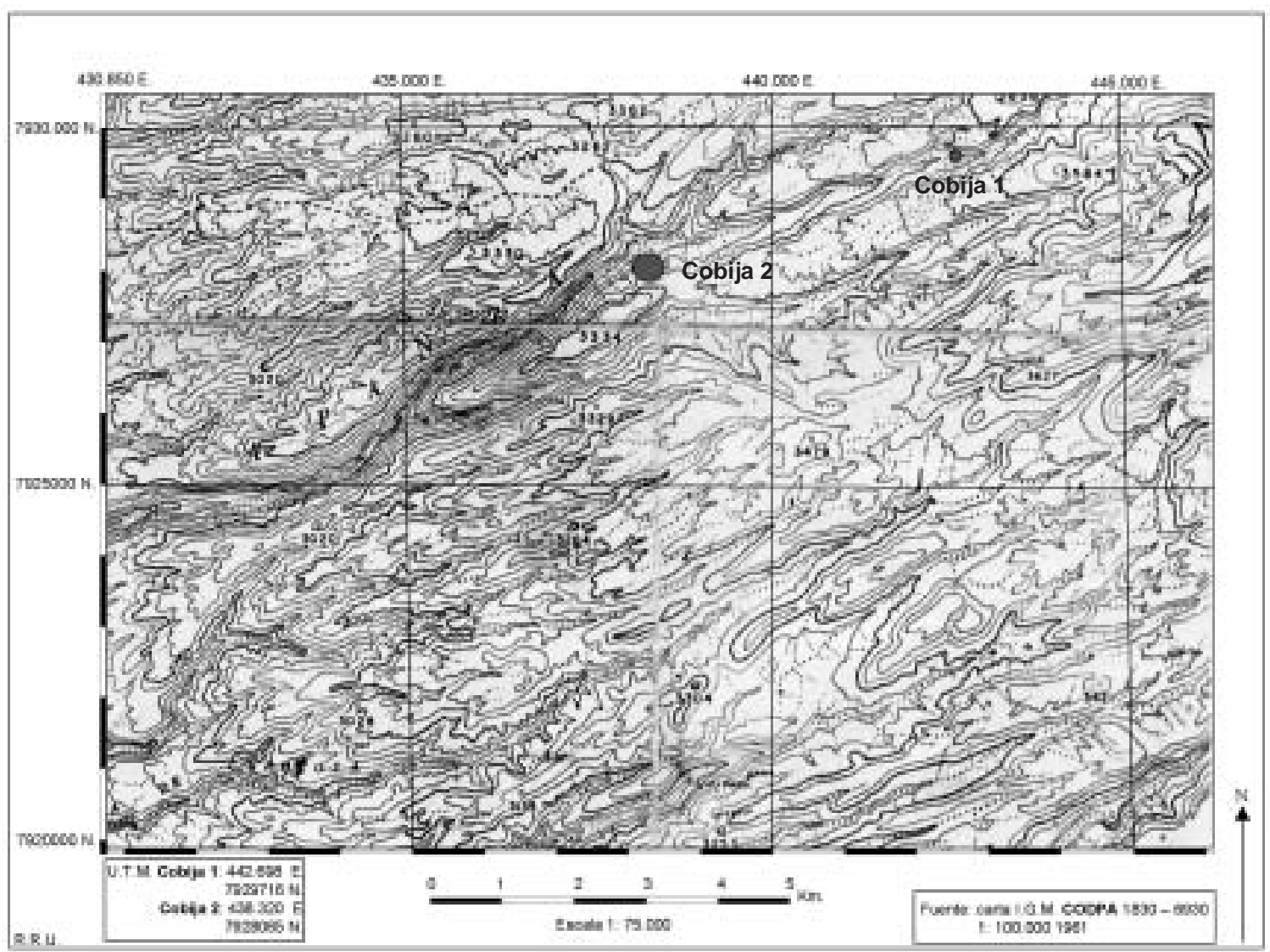

Figura 2. Ubicación geográfica de los sitios Cobija-1 y Cobija-2 en los altos de la quebrada de Apanza o Cobija. Fuente: carta IGM Codpa 1830-6930 / 1: $100.000 / 1961$.

presentan elevaciones aplomadas en sentido contrario a la pendiente, otorgándoles solidez y resguardo de deterioro por derrumbe. No son muy claras las vías de comunicación entre los recintos, por lo que parece probable que se hayan utilizado vías naturales cuyas evidencias han desaparecido por la erosión. Para la edificación de los recintos se aprovecharon las irregularidades del cerro, es decir, se utilizaron creativamente los afloramientos rocosos para crear en ciertos tramos pircados de muros.

En este asentamiento se reconocieron cuatro sectores (Figura 3), de acuerdo a sus características arquitectónicas, distribución espacial, diagnóstico superficial de suelos y evidencias culturaleseconómicas halladas en áreas internas y externas (Figura 4).

Sector A. Se emplaza en la cima, y las estructuras están más próximas unas de otras. Los accesos se relacionan a las facilidades que el terreno ofrece, no respondiendo todos a una misma orientación. Desde el lugar del poblado se tiene un amplio dominio visual de la quebrada de Cobija; sin embargo, no hay evidencias de construcción de muro perimetral que le podría conferir un aire defensivo tipo pucara. Tampoco se observa la construcción de un recinto de convergencia social o ceremonial.

Las características físicas del cerro, un montículo abrupto de conformación rocosa, permitió que se seleccionaran los recodos y espacios más benignos para obtener nivelaciones del suelo ocupacional. Las formas predominantes de los recintos son ovoidales y circulares, con muros de doble hilada de piedra. Los recintos de orden económico como los silos, aunque son escasos, se construyeron a partir del afloramiento de la roca madre, aprovechándose las condiciones topográficas del terreno así como la presencia de grandes bloques utiliza- 


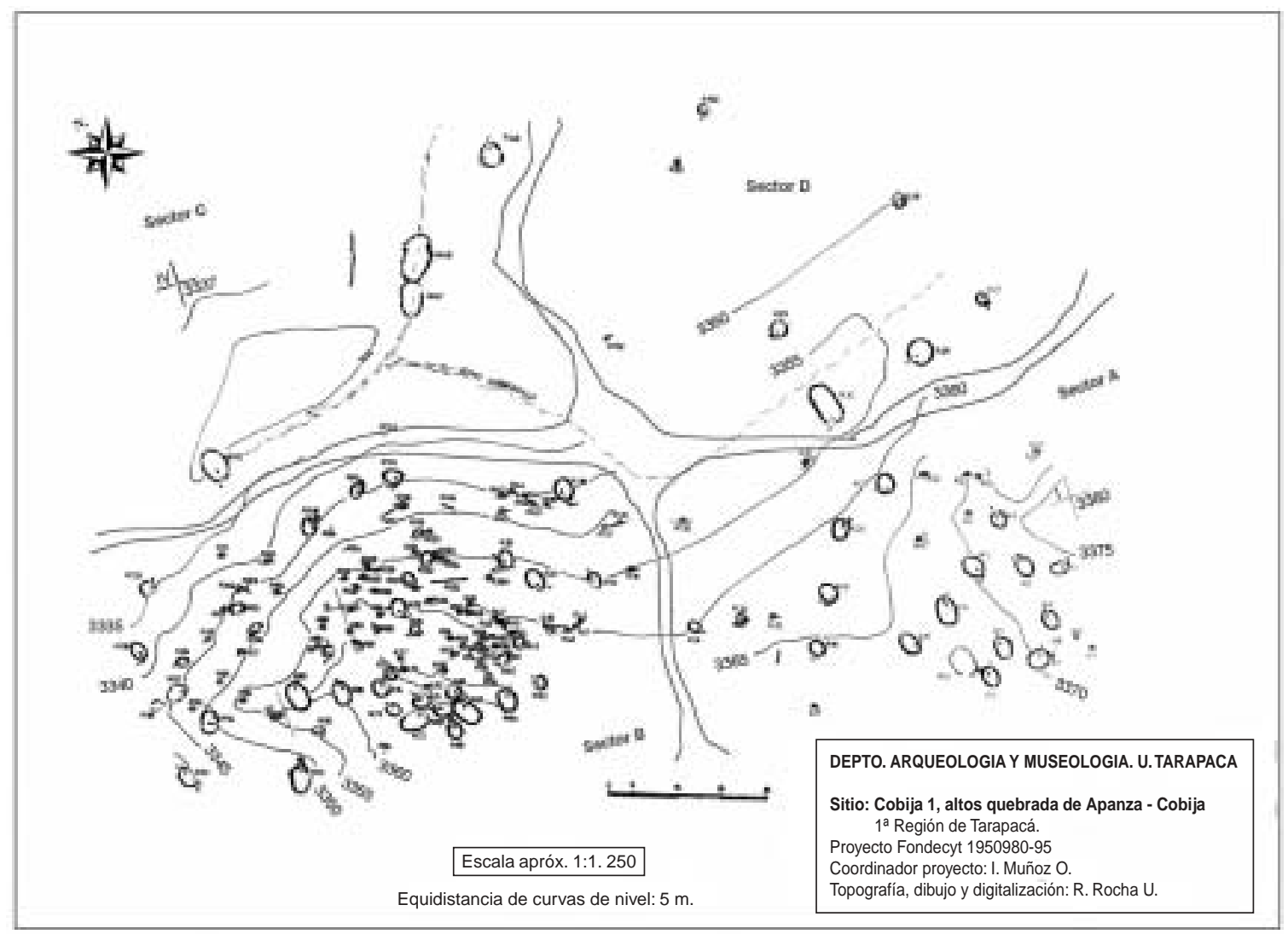

Figura 3. Sectorización del sitio Cobija-1.

dos para estructurar paredes interiores y exteriores. Un recinto muestra que estos bloques fueron dispuestos verticalmente confiriendo una mediana altura. Los bloques están combinados con segmentos de muros de doble hilada de piedras para constituir estructuras de hasta $7 \mathrm{~m}$ de diámetro.

Sector B. Al igual que en el Sector A, predominan las estructuras de forma circular y ovoidal, construidas con muros de doble hilada de piedras, rellenos de sedimentación. Los accesos están claramente definidos, incluso algunos recintos conservan prolongaciones a modo de pasillos, que van al exterior o interior de la estructura. Los muros son relativamente bajos y gruesos. Este sector es espacialmente estrecho, lo que obligó a aproximar un recinto con otro, y como resultado de ello, se aprecian vías de comunicación entre las habitaciones. Los accesos se orientan hacia el oriente. El piso ocupacional de los recintos conserva fragmentos de cerámica sin decoración ni engobe, en los que predominan los tonos de color café y naranja, como consecuencia de la cocción. También se pudo registrar en un recinto instrumentos de molienda, como batanes y manos fragmentadas. Los pozos de almacenaje fueron construidos preferentemente hacia el borde norte de la cima, aprovechando el escarpe del suelo rocoso. Son de forma circular, abovedados y muy bien conservados, y los muros son de doble hilada de piedras con relleno de sedimentación. Todos son construcciones sobre superficie, claramente identificables a cierta distancia. Por otra parte, técnicamente, la consolidación de las piedras se logró por un prolijo acuñamiento para evitar derrumbes y filtraciones, y, en otros casos, se utilizó argamasa como mortero.

Sector C. Ocupa la pendiente norte del cerro, cuya compleja topografía con una pendiente pronunciada condicionó la disposición de los recintos. Se constataron seis cotas de edificaciones desde la base de la quebradilla hasta la cima, cubriendo una altura de $10 \mathrm{~m}$. El estado de conservación de los recintos es bueno, lo que permite analizar la técnica constructiva. Los recintos obtienen sus 
IVAN MUÑOZ O.

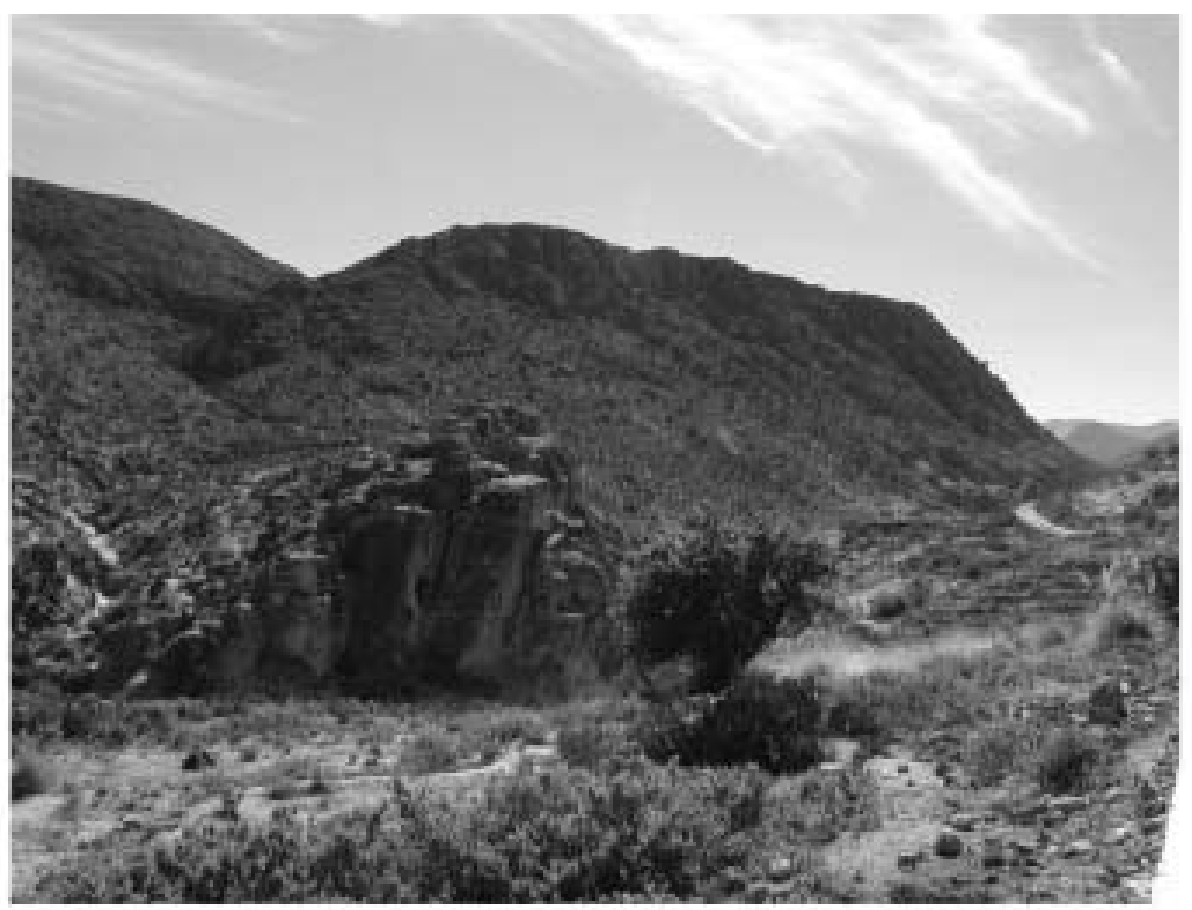

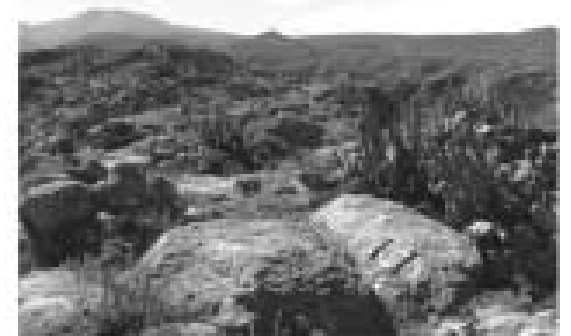

$b$

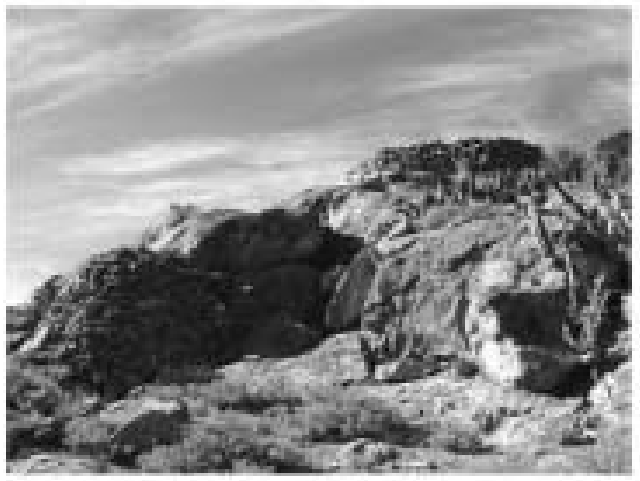

d

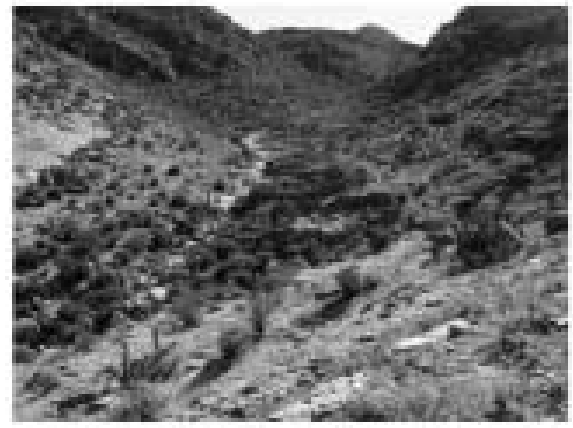

0

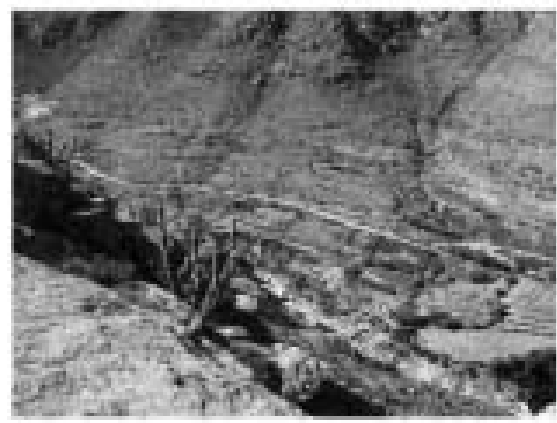

e

Figura 4. Cobija-1. a) Promontorio accesible a emplazamiento de edificaciones; b) Distribución de recintos habitacionales y silos en sectores A y B; c) Segmento de red vial, transecto Cobija-Tignamar, asociado a corrales; d) Habitaciones con técnica de aterrazamiento en afloramientos rocosos; e) Terrazas de cultivo y canales de regadío en lecho de quebrada, margen sur. 
mayores dimensiones de este a oeste y la menor longitud en sentido norte-sur, por ende, las formas son ovales. Los muros están construidos con doble hilada de piedras con sedimentación y grava en su interior. Los accesos tienen orientaciones oeste-este. Bloques de gran volumen han sido utilizados como jambas, y otros grandes bloques han sido la base de edificación tendiendo siempre a aplomarlos en dirección contraria a la pendiente. No hay existencia de mortero para acuñarlos, siendo la mampostería delicada, resultando un muro fuerte y resistente. Un considerable número de pozos de almacenaje se aglutina hacia el oeste; los recovecos del terreno determinaron estructuras circulares, pequeñas, pero de alturas considerables. El cuerpo del edificio es abovedado, sobre superficie, con algunos rodados productos de derrumbes. Hubo empleo de mortero pero actualmente, producto de la erosión, es muy difícil determinarlo pues tiende a confundirse con simple barro de escurrimiento. Para sellar las aberturas se emplearon lajas y tierra.

Sector D. Corresponde a un conjunto de corrales ubicados en la base de la ladera norte del poblado, y también en el límite sur del lecho de la quebradilla. Los recintos son de planta circular, con pircados muy rudimentarios, construidos con una o dos hiladas de piedras. La superficie del piso interno no parece haber sido nivelada. La única preocupación fue delimitar un amplio espacio para abrigar animales, posiblemente llamas y alpacas. Tres de estas estructuras están emplazadas hacia lo alto de la quebradilla limitando con su cauce seco. A diferencia de las estructuras del lado oeste, éstas aún conservan una técnica más depurada en las edificaciones aprovechando incluso la existencia de rocas de gran tamaño. Remontando desde el lecho hacia el norte se aprecia un pircado extenso y simple que claramente sirve de solera o muro de contención a un camino que proviene de otros lugares de la sierra. El muro es bastante sinuoso como consecuencia de la topografía del lugar, incluso su suelo interno carece de sedimento, por lo que puede transitarse sobre la roca natural.

En síntesis, podemos señalar que el asentamiento de Cobija-1 se caracteriza por: a) una planificación y selectividad del espacio, a pesar de algunas características topográficas adversas; b) una posición estratégica que le confiere un amplio dominio del área, especialmente de la quebrada de Cobija como afluente principal del recurso agua; c) una clara armonización de los espacios habitacionales y económicos tales como pozos de almacenaje y corrales; d) un sector económico potenciado por la agricultura ocupa la banda sur de la quebrada de Cobija, de la cual se tiene un amplio dominio visual desde la cima del poblado; e) nexos de comunicación vial con otros centros poblacionales de tierras más altas y de sectores bajos de la quebrada como el poblado Cobija2 ; f) ausencia de muros perimetrales defensivos, lo que puede indicar de una coexistencia poblacional pacífica durante el Período Tardío.

La Tabla 1 muestra que la mayoría de las estructuras, al parecer, tuvo una función relacionada al espacio habitacional (viviendas) y de almacenaje (silos), aunque un número alto no presenta evidencias de haber sido ocupado. Las formas más representativas son ovales y, en menor porcentaje, circulares y rectangulares, especialmente las estructuras habitacionales. Tanto las habitaciones como los silos fueron construidos con muros de doble hilada de piedras, utilizándose en un alto porcentaje grava como relleno. Los ingresos a las estructuras habitacionales tienen diferentes orientaciones. Un número reducido presenta divisiones interiores y los tamaños de las viviendas van desde los $5 \mathrm{~m}$ a $8 \mathrm{~m}$ y los silos de $1 \mathrm{~m}$ a $3 \mathrm{~m}$.

La cerámica de Cobija-1 corresponde a una muestra compuesta de 304 fragmentos obtenida de una recolección superficial de los recintos $8,33,46$, $78,82,105,128$ y 151 del poblado. Para este análisis se consideraron tres variables: pasta, formas y decoración. La clasificación se basó en la granulometría de las inclusiones, color y mineralogía. Como referencia se utilizó el trabajo de Santos y colaboradores (1996 Ms) quienes determinaron 10 estándares de pastas en los asentamientos de la sierra de Arica. Según este análisis los grupos más representativos corresponden a los estándares 102, 103 y 104.

En Cobija-1, se aprecia gran frecuencia de pasta estándar 104 (79\%), la cual se caracteriza por poseer inclusiones blancas; presenta color de quema anaranjada, es poco quebradiza y deleznable, con una cocción descuidada, lo que permite una superficie tanto interna como externa reducida. Otros estándares de pasta fueron el 105 (12\%), 103 (8\%) y el $102(1 \%)$. Estos estándares de pasta son más quebradizos y porosos que el 104 (Gráfico 1). 


\begin{tabular}{|c|c|c|}
\hline Total estructuras: 151 & $\mathbf{N}^{0}$ Estructura & $\%$ \\
\hline \multicolumn{3}{|l|}{ Función } \\
\hline Habitacional & 75 & 49.67 \\
\hline Almacenaje (silos) & 51 & 33.77 \\
\hline Ceremonial (plaza) & 1 & 0.66 \\
\hline Económica (corrales) & 4 & 2.65 \\
\hline Indeterminada & 20 & 13.25 \\
\hline Total & 151 & 100.00 \\
\hline \multicolumn{3}{|l|}{ Formas } \\
\hline Oval (habitacional) & 52 & 34.44 \\
\hline Oval (silos) & 41 & 27.15 \\
\hline Circular (habitacional) & 8 & 5.30 \\
\hline Circular (silos) & 21 & 13.91 \\
\hline Rectangular (habitacional) & 10 & 6.62 \\
\hline Semirrectangular (corrales) & 4 & 2.65 \\
\hline Semirrectangular (plaza) & 1 & 0.66 \\
\hline Indeterminada & 14 & 9.27 \\
\hline Total & 151 & 100.00 \\
\hline \multicolumn{3}{|l|}{ Sistema constructivo } \\
\hline Muro doble hiladas de piedras (habitación) & 62 & 41.06 \\
\hline Muro doble hiladas de piedras (silos) & 75 & 49.67 \\
\hline Muro una hilada de piedras (habitación) & 5 & 3.31 \\
\hline Muro una hilada de piedras (silos) & 4 & 2.65 \\
\hline Muro una hilada de piedras (corral) & 1 & 0.66 \\
\hline Muro triple hiladas de piedras (corral) & 4 & 2.65 \\
\hline Total & 151 & 100.00 \\
\hline \multicolumn{3}{|l|}{ Técnicas } \\
\hline Muro superposición de piedras sin argamasa ni grava (habitacional) & 18 & 11.92 \\
\hline Muro superposición de piedras sin argamasa ni grava (silos) & 10 & 6.62 \\
\hline Muro superposición de piedras sin argamasa ni grava (corrral) & 2 & 1.32 \\
\hline Uso de grava (habitacional) & 51 & 33.77 \\
\hline Uso de grava (silos) & 67 & 44.37 \\
\hline Indeterminada & 3 & 1.99 \\
\hline Total & 151 & 100.00 \\
\hline \multicolumn{3}{|l|}{ Rasgos constructivos específicos } \\
\hline Habitaciones con divisiones interiores & 2 & 1.32 \\
\hline Indeterminada & 149 & 98.68 \\
\hline Total & 151 & 100.00 \\
\hline \multicolumn{3}{|l|}{ Orientación de las entradas } \\
\hline Ingreso habitaciones dirección suroeste & 12 & 7.95 \\
\hline Ingreso habitaciones dirección este & 10 & 6.62 \\
\hline Ingreso habitaciones dirección noreste & 11 & 7.28 \\
\hline Ingreso habitaciones dirección sur & 10 & 6.62 \\
\hline Ingreso habitaciones dirección noroeste & 18 & 11.92 \\
\hline Indeterminada & 90 & 59.60 \\
\hline Total & 151 & 100.00 \\
\hline \multicolumn{3}{|l|}{ Dimensiones } \\
\hline Estructura habitacional grande $(9-5 \mathrm{~m})$ & 34 & 22.52 \\
\hline Estructura habitacional mediana $(5-3 \mathrm{~m})$ & 61 & 40.40 \\
\hline Indeterminada & 56 & 37.09 \\
\hline Total & 151 & 100.00 \\
\hline
\end{tabular}

Tabla 1. Análisis porcentual de las estructuras Cobija-1. 


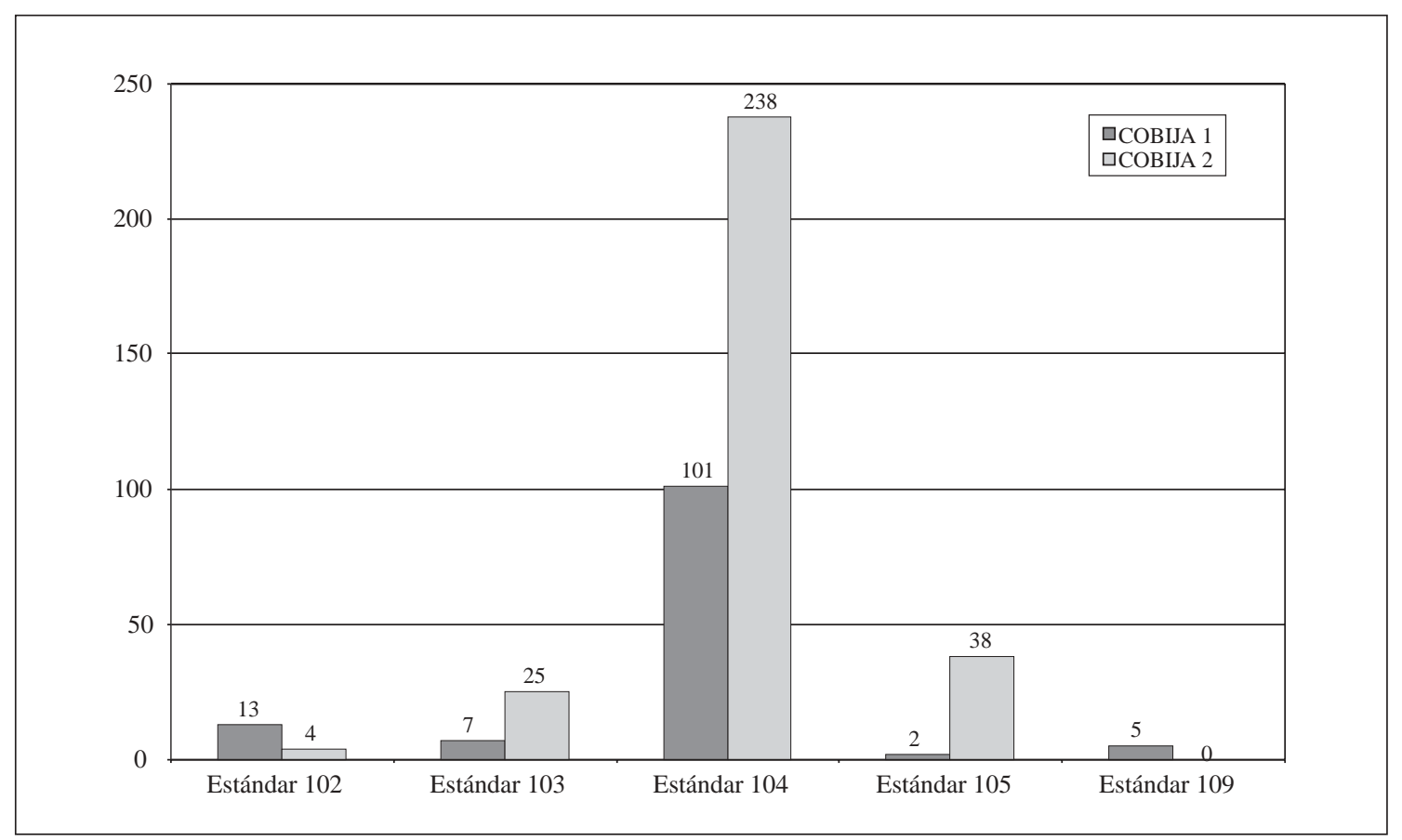

Gráfico 1. Estándares de pasta de Cobija-1 y Cobija-2.

Para las formas se utilizó la tipología propuesta para el valle de Lluta (Santoro et al. 2001), donde el grueso de los fragmentos corresponde a bordes, aunque también algunas formas se infirieron a través de fuentes bibliográficas (Dauelsberg 1961; Uribe 1998, 1999) (Tabla 2).

El mayor número de fragmentos analizados en Cobija-1 corresponde a la parte central del cuerpo de las vasijas (90\%). Las formas más frecuentes fueron las ollas $(6 \%)$ y pucos $(3 \%)$, posiblemente relacionadas con actividades domésticas tanto para depositar alimentos como para almacenar productos y jarros globulares (1\%). Estas formas son también indicadores culturales, así, por ejemplo, las ollas y jarros están asociados al Desarrollo Regional Costero (Cultura Arica), en cambio, los pucos se asocian más a tradiciones altiplánicas preincaicas (Gráfico 2).

Respecto a los estilos decorativos, su análisis se realizó de acuerdo a las características superficiales de pintura, recubrimiento y decoración. Los estilos, considerando la metodología propuesta por Muñoz y Santos (1998) para el valle de Miñita, fueron agrupados en grandes tradiciones, lo cual hizo posible su identificación en el registro arqueológico. Los estilos reconocidos dentro de un universo de cerámica mayoritariamente sin decoración son los de la Tradición Serrana con un 4\% y los de la Tradición Negro sobre Rojo con un 2\% (Gráfico 3).

En suma, el análisis de los componentes cerámicos de Cobija-1 permite plantear que el acento estuvo en la confección local de tiestos. Esta población si bien pudo haber interactuado con los incas, éstos no habrían influido a través de bienes o manufacturas. En este asentamiento son representativas las tradiciones Negro sobre Rojo y Serrana, y queremos destacar dentro de esta última la presencia del estilo Charcollo como representante de la identidad serrana, la cual se habría manifestado desde el 1100 DC, constituyéndose en un estilo cerámico representativo del desarrollo cultural en las cabeceras de valle y sierra de Arica.

\section{Modelo de asentamiento de Cobija-2}

El poblado Cobija-2 ha sido construido en siete a ocho niveles de altura, llegando al plano en la base de la ladera. En esta base se construyó un tambo, que fue orientado hacia el sector noroeste del poblado. En este asentamiento se han reconocido tres sectores (Figura 5): 
IVAN MUÑOZ O.

\begin{tabular}{|lcccc|}
\hline Formas inferidas & Cobija-1 & \% $\left(\mathbf{n}^{\mathbf{0}}\right.$ fragmentos=273) & Cobija-2 & \% $\left(\mathbf{n}^{\mathbf{0}}\right.$ fragmentos= 148) \\
\hline Olla & 19 & 6.96 & 11 & 7.43 \\
Puco & 9 & 3.30 & 2 & 1.35 \\
Jarro Globular & 2 & 0.73 & 1 & 0.68 \\
Escudilla & - & - & 7 & 4.73 \\
Plato & - & - & 2 & 1.35 \\
Aríbalo & - & - & 2 & 2.03 \\
Base & - & - & 2 & 1.35 \\
Asa & - & - & 1 & 0.68 \\
Preforma & - & $\mathbf{1 0 . 9 9}$ & $\mathbf{3 1}$ & $\mathbf{2 0 . 9 5}$ \\
Total & $\mathbf{3 0}$ & & & \\
\hline
\end{tabular}

Tabla 2. Formas de cerámica.

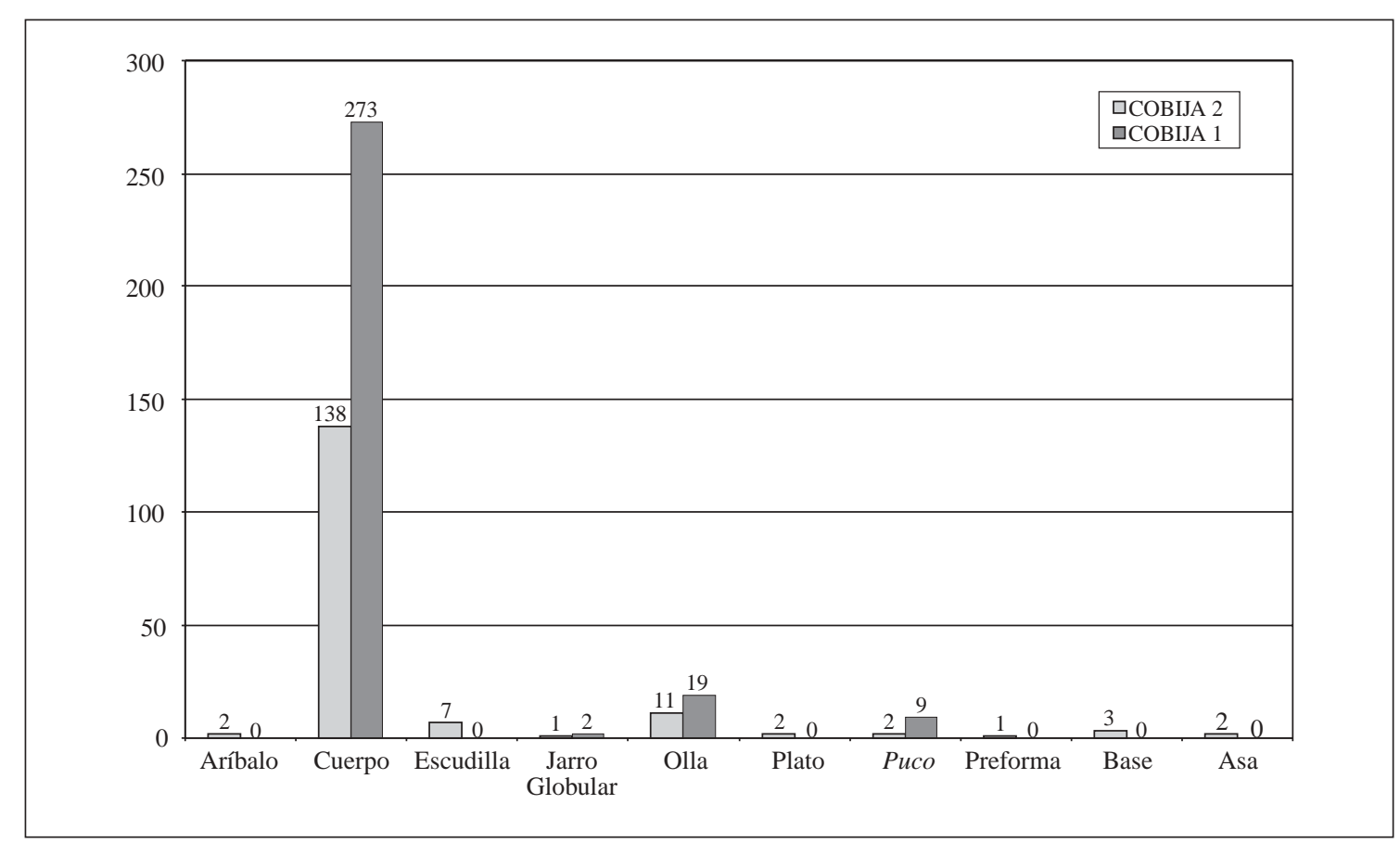

Gráfico 2. Formas de cerámica en Cobija-1 y Cobija-2.

Sector A. Las estructuras habitacionales se emplazan en las cotas superiores de la ladera sur de la quebrada de Cobija, las que se encuentran muy destruidas, casi a nivel de cimientos (Figuras 6a y b). Su forma es circular y oval, con muros de doble hilada cuya altura al momento de ser ocupados es posible que haya oscilado entre $1.20 \mathrm{~m}$ a $1.30 \mathrm{~m}$, de acuerdo al recinto 33 . Se utilizaron cantos rodados y grava como relleno. La edificación de los recintos responde a un ordenamiento orgánico. Algunas estructuras presentan accesos en su interior con grandes cantos rodados utilizados como peldaños. En general, en cada una de las estructu- ras, tanto afuera como adentro, se observan desechos de talla de basalto.

En el sureste del asentamiento existen estructuras similares a las descritas, determinando un tercer complejo habitacional que incluye a los recintos 15 y 16, adosados unos con otros. Al igual que los complejos anteriores, la conservación de estas estructuras es regular, con mucho abatimiento de los muros. El recinto 13 conserva en el extremo sureste un bloque compacto dispuesto verticalmente a modo de jamba, el que define un acceso por el suroeste. Orientados hacia el este, encontramos 


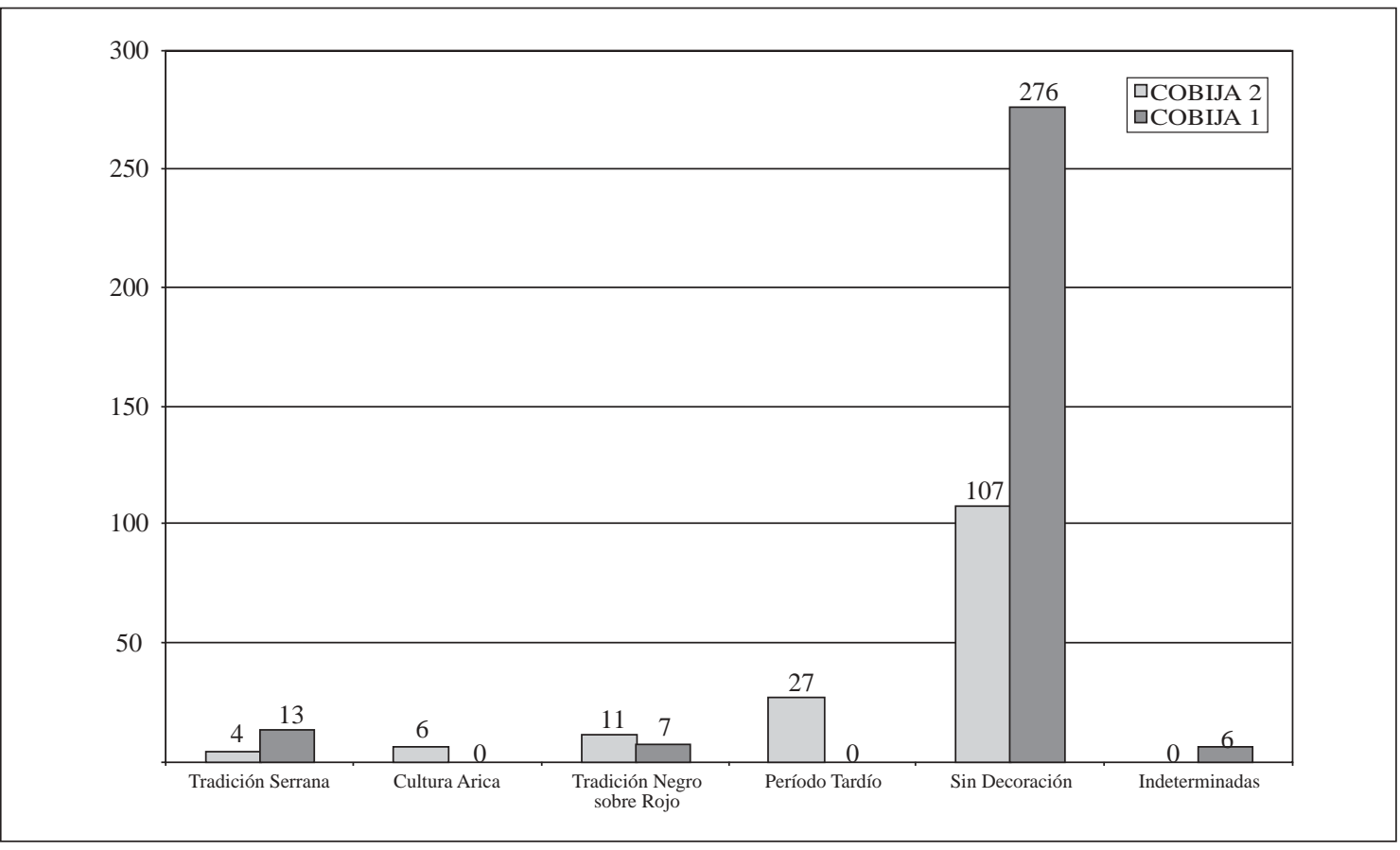

Gráfico 3. Estilos decorativos de la cerámica de Cobija-1 y Cobija-2.

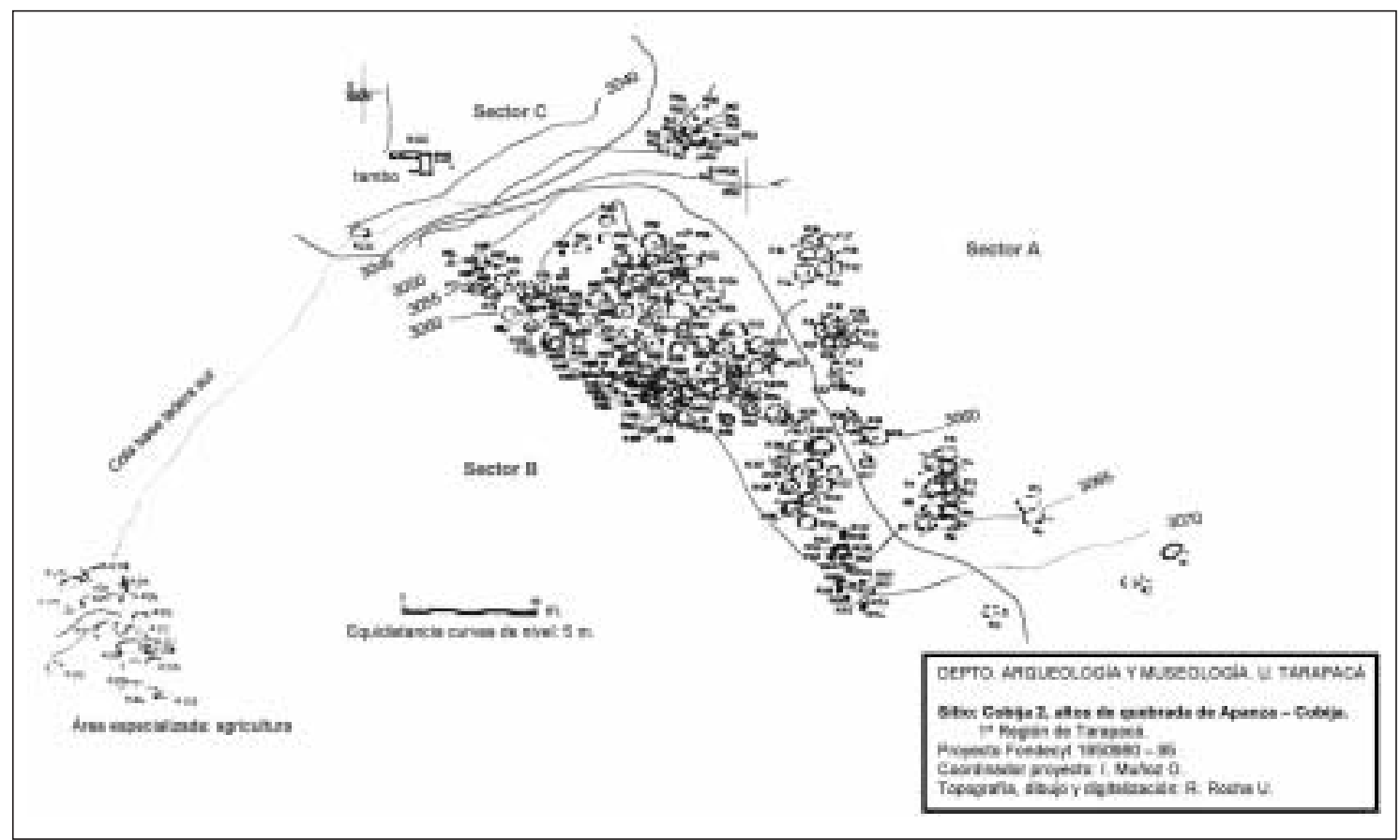

Figura 5. Sectorización del sitio Cobija-2.

cinco recintos de forma rectangular. Los muros son de doble hilada de piedras, construidos con cantos pequeños, los cuales en la actualidad han rodado producto de derrumbes hacia el exterior e interior de los recintos. Algunas características específicas se ven en los recintos 1 y 2 donde se 


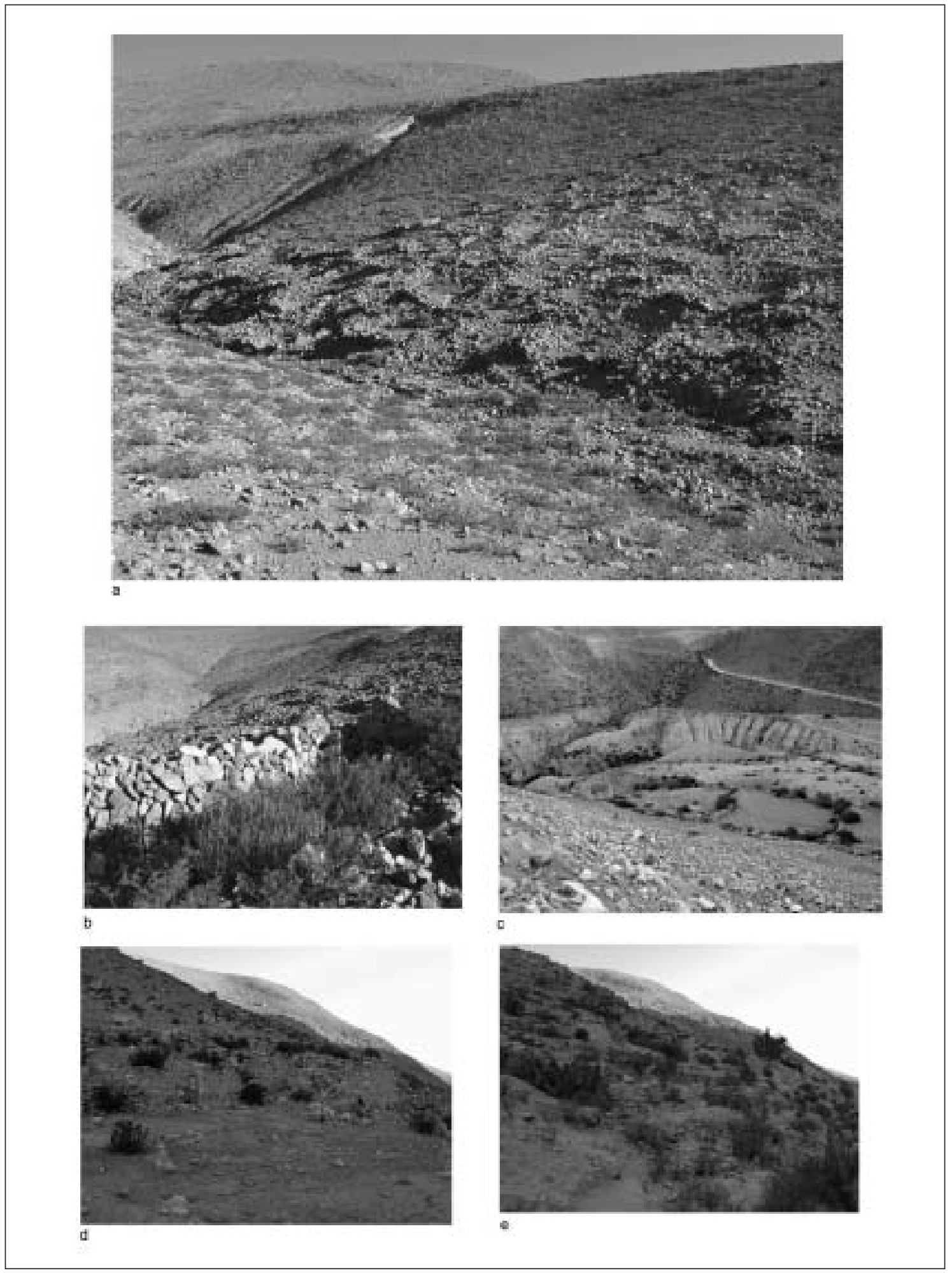

Figura 6. Cobija-2. a) Emplazamiento de habitaciones, silos y corrales en Sector A; b) Mampostería en recintos habitacionales del Sector A; c) Area destinada a habitaciones y pozos de almacenaje en Sector B; d) Tambo en Sector C; e) Area económica destinada a producción agrícola. 
conservan accesos con peldaños orientados hacia el sureste. En el recinto 4 se aprecian dos espacios funcionales en su interior.

Sector B. Está separado del Sector A por una quebradilla de orientación norte-sur, afluente de la quebrada principal. Las estructuras se desplazan desde cotas no muy altas hacia la base del cerro. Las habitaciones son semirrectangulares debido a lo curvo de las esquinas (Figura 6c). Los muros son de doble hilada de piedras con relleno sedimentario. Los cimientos en algunos casos están dados por acuñamiento de bloques mayores. Producto de la proximidad de las viviendas han quedado estrechas vías de comunicación a manera de pasillos. En las cotas superiores se observa que bajo superficie construyeron pozos de almacenaje de tamaño reducido, sin embargo algunos edificios ganan altura sobre superficie (p.e., recinto 160). El recinto 12 posee, además, un acceso con pasillo.

Sector $C$. Corresponde al tambo, edificio que está construido por recintos de planta rectangular con diferentes orientaciones; por sus ejes de mayor longitud, norte-sur, este-oeste los muros son gruesos y de doble hilada de piedras, y sus alturas promedian los $2.20 \mathrm{~m}$ (Figuras $6 \mathrm{~d}$ y e). Las esquinas están tratadas en ángulos rectos y bien consolidadas. La techumbre probablemente fue de paja brava y con inclinaciones a dos aguas. Casi la totalidad de los muros, tanto en las superficies externas e internas han sido estucados, probablemente con mortero. En la preparación de este mortero notamos presencia de ceniza y tierra de color gris blanquecina. Este complejo está compuesto por cinco recintos, el de mayor dimensión está orientado de norte a sur, mientras que los más pequeños están orientados de este a oeste. Los accesos son de forma trapezoidal, tienen un estrecho dintel y una amplia base (p.e., recinto 202). El recinto 4 presenta un acceso compuesto por tres peldaños. También es posible observar que los muros están aplomados en dirección contraria a la pendiente. Los terraplenes amurallados han sido delimitados por el costado oeste del recinto 202 prolongándose hacia el edificio mayor. Las estructuras de este tambo responden a una función habitacional, y un amplio espacio abierto que se ubica hacia el norte del tambo puede sugerir funciones de convergencia social; además, por este lugar hay senderos que comunican este poblado con otros, ya sea del mismo valle como Cobija-1 o de pisos más bajos como el poblado prehispánico de Timar. La presencia de cerámica negro sobre engobe rojo y naranja hallada en los alrededores del tambo, sugeriría un contacto entre poblaciones incanizadas y nativas del valle. Dicha interacción pudo haberse gestado en las cercanías del edificio donde al parecer hubo intercambio y ceremonias.

Respecto al tambo mismo, este parece haber sido reacondicionado. El estuco empleado en los muros evidencia el empleo de material orgánico vegetal, además de cenizas y restos de cal o arcilla blanquecina.

En síntesis, en Cobija-2 podemos diferenciar tres sectores: 1) el Sector A, que presenta accesos orientados al este, y algunos recintos con subdivisiones internas. Los pozos de almacenaje se hallan en cotas inferiores de la ladera orientados hacia el cauce; 2 ) el Sector B, el de mayor concentración de recintos, respondiendo a una urbanización planificada, un crecimiento orgánico con bondades topográficas adecuadas para levantar viviendas. Probablemente sea esta última la causa principal para que se trabajaran las cotas medias de la ladera a una altura promedio de $40 \mathrm{~m}$ a $50 \mathrm{~m}$; 3) el Sector C, representa el momento final de la ocupación prehispánica en el cual se habría producido la coexistencia entre poblaciones locales e incanizadas; éstas últimas provendrían del Altiplano Circumtiticaca, a juzgar por la alfarería.

Por el poblado pasa un sendero el cual está inserto dentro de una red de caminos que se desplazan por la sierra, comunicando los valles bajos (p.e., Timar) y la puna a través de Timalchaca.

En cuanto a la función, la Tabla 3 muestra que el mayor número de estructuras corresponde a habitaciones y pozos de almacenaje. Las formas más representativas para habitaciones y silos son ovales y circulares. Respecto de la construcción de las estructuras, tanto habitaciones como silos han sido edificados por muros de doble hilada de piedras rellenos de grava. Algunas habitaciones mejor conservadas tienen peldaños de ingreso, los que presentan diferentes orientaciones: sureste, sur, oeste y norte. El tamaño de las estructuras habitacionales varía de $9 \mathrm{~m}$ a $5 \mathrm{~m}$ y los silos de $1 \mathrm{~m}$ a $3 \mathrm{~m}$.

Por otra parte, el análisis de los estilos, pasta y formas de la cerámica de Cobija-2, permite definir una ocupación que se desarrolló entre 1200 


\begin{tabular}{|c|c|c|}
\hline Total estructuras: 220 & $\mathbf{N}^{0}$ Estructura & $\%$ \\
\hline \multicolumn{3}{|l|}{ Función } \\
\hline Habitacional & 97 & 44.1 \\
\hline Almacenaje (silos) & 113 & 51.4 \\
\hline Ceremonial (plaza) & 1 & 0.5 \\
\hline Económica (corrales) & 6 & 2.7 \\
\hline Indeterminada & 3 & 1.4 \\
\hline Total & 220 & 100.0 \\
\hline \multicolumn{3}{|l|}{ Formas } \\
\hline Oval (habitacional) & 85 & 38.6 \\
\hline Oval (silos) & 87 & 39.5 \\
\hline Circular (habitacional) & 5 & 2.3 \\
\hline Circular (silos) & 28 & 12.7 \\
\hline Rectangular (habitacional) & 11 & 5.0 \\
\hline Semirrectangular (corrales) & 2 & 0.9 \\
\hline Semirrectangular (plaza) & 1 & 0.5 \\
\hline Indeterminada & 1 & 0.5 \\
\hline Total & 220 & 100.0 \\
\hline \multicolumn{3}{|l|}{ Sistema constructivo } \\
\hline Muro doble hiladas de piedras (habitación) & 97 & 44.09 \\
\hline Muro doble hiladas de piedras (silos) & 110 & 50.00 \\
\hline Muro una hilada de piedras (habitación) & 8 & 3.64 \\
\hline Muro triple hiladas de piedras (habitación) & 5 & 2.27 \\
\hline Total & 220 & 100.00 \\
\hline \multicolumn{3}{|l|}{ Técnicas } \\
\hline Muro superposición de piedras sin argamasa ni grava (habitacional) & 27 & 12.27 \\
\hline Muro superposición de piedras sin argamasa ni grava (silo) & 11 & 5.00 \\
\hline Muro superposición de piedras sin argamasa ni grava (corrral) & 4 & 1.82 \\
\hline Uso de grava (habitacional) & 63 & 28.64 \\
\hline Uso de grava (silo) & 51 & 23.18 \\
\hline Uso de argamasa (habitacional) & 7 & 3.18 \\
\hline Uso de argamasa (silo) & 15 & 6.82 \\
\hline Indeterminada & 42 & 19.09 \\
\hline Total & 220 & 100.00 \\
\hline \multicolumn{3}{|l|}{ Rasgos constructivos específicos } \\
\hline Habitación con peldaño de ingreso & 12 & 5.45 \\
\hline Indeterminada & 208 & 94.55 \\
\hline Total & 220 & 100.00 \\
\hline \multicolumn{3}{|l|}{ Orientación de las entradas } \\
\hline Ingreso habitaciones dirección sureste & 28 & 12.73 \\
\hline Ingreso habitaciones dirección suroeste & 15 & 6.82 \\
\hline Ingreso habitaciones dirección norte & 11 & 5.00 \\
\hline Ingreso habitaciones dirección noreste & 6 & 2.73 \\
\hline Ingreso habitaciones dirección sur & 3 & 1.36 \\
\hline Ingreso habitaciones dirección noroeste & 2 & 0.91 \\
\hline Indeterminada & 155 & 70.45 \\
\hline Total & 220 & 100.00 \\
\hline \multicolumn{3}{|l|}{ Dimensiones } \\
\hline Estructura habitacionales grandes $(9-5 \mathrm{~m})$ & 29 & 13.18 \\
\hline Estructura corrales grandes & 3 & 1.36 \\
\hline Estructura habitacional mediana $(5-3 \mathrm{~m})$ & 73 & 33.18 \\
\hline Estructura silo medianas $(3-1 \mathrm{~m})$ & 115 & 52.27 \\
\hline Total & 220 & 100.00 \\
\hline
\end{tabular}

Tabla 3. Análisis porcentual de las estructuras Cobija-2. 
DC y 1500 DC. La muestra proviene de una recolección superficial conformada por 148 fragmentos provenientes de diferentes recintos. En cuanto a las pastas, se aprecia una gran frecuencia del estándar 104 (79\%) que contiene inclusiones blancas uniformes. La pasta presenta un color de quema anaranjada, es menos quebradiza y deleznable que las del estándar 105 (2\%), que presenta una cocción un tanto descuidada que permite observar una superficie tanto interna como externa reducida. Otros estándares de pasta identificados son el $103(5 \%), 109$ (4\%) y $102(10 \%)$. Este último se asocia a la cerámica del Período Tardío (ver Gráfico 1).

Las formas más representativas fueron las ollas (7\%) y escudillas (4\%), posiblemente confeccionadas para actividades domésticas, como contener comidas y líquidos. En menor cantidad se observan pucos (1.3\%), platos (1.3\%) y aríbalos $(1.3 \%)$. Cabe mencionar que la diferencia entre escudillas, pucos y platos está dada principalmente por la altura respecto de su máximo diámetro (ver Rice 1987). También fueron halladas bases (2\%) de formas planas y cóncavas. Las tradiciones tardías vinculadas a la presencia inca en la quebrada se asocian a formas de escudillas y aríbalos, las que encontramos en el área donde se construyó el tambo asociadas a arquitectura inca (ver Tabla 2 y Gráfico 2).

Los estilos reconocidos en Cobija- 2 corresponden a la Tradición Tardía, que está presente con un $17 \%$, a la Tradición Negro sobre Rojo, con un $7 \%$, a la Tradición Serrana con un 3\%, y a la Cultura Arica con un 4\% (ver Gráfico 3).

En síntesis, el análisis de la cerámica indica que Cobija-2 fue un asentamiento ocupado por una población local (Tradición Serrana y Negro sobre Rojo y Cultura Arica) que interactuó con los incas, los que habrían influido a través de bienes y arquitectura como se aprecia en la cerámica de Tradición Tardía (estilos Saxamar e Inca Provincial), junto a la construcción de un tambo. En Cobija-2 se hayan formas de aríbalo, plato y escudilla, ausentes en Cobija-1 (Figuras 7a, b y c).

\section{Fechados TL obtenidos de Cobija y discusión cronológica}

Los fechados obtenidos para los asentamientos de Cobija-1 y Cobija-2 corresponden a dataciones logradas por el método de la termoluminiscencia (TL) (Figuras 8a, b y c). Del asentamiento Cobija-1 se tomaron dos muestras de cerámica: la muestra UCTL-840, proveniente del recinto 37, arrojó una fecha de 1440 DC. Corresponde a un fragmento engobado a tres colores (negro, blanco y rojo) cuya superficie interna presenta un alisado por brochado sin color ni decoración, y la externa, un pulido y bruñido muy disparejo. La muestra UCTL-841 también proviene del recinto 37 y dio una fecha de 1410 DC. Presentaba un engobado exterior de color rojo y decoración de líneas semionduladas en negro. El tratamiento de superficie en su cara interna es alisado y brochado sin engobe, color natural de la pasta, y su cara externa es pulida y bruñida en forma descuidada. Respecto a Cobija-2, la muestra de cerámica UCTL-839 proviene del tambo, y la fecha obtenida fue de $1480 \mathrm{DC}$; se trata de una escudilla con la superficie interior engobada a dos colores (blanco y negro) y decorada con líneas paralelas delgadas y cruces en negro en el contorno del borde. Este fragmento presenta excelente pasta y fino trabajo decorativo (ver Tabla 4).

Las fechas indican que ambos asentamientos coexistieron durante los momentos de influencia inca, en los que se habría construido el tambo y se habría manufacturado la cerámica estilo Saxamar o Inca Pacaje. Sin embargo, por la arquitectura de los recintos habitacionales y la cerámica del área habitacional, da la impresión que Cobija-2 fue una aldea que habría comenzado a edificarse con anterioridad a la ocupación inca, insertándose en la línea de los poblados serranos de planta oval, que emergieron después de la desintegración de Tiwanaku alrededor del 1200 DC,

\begin{tabular}{|lcccc|}
\hline Sitio & Muestra Laboratorio & Descripción & Edad & Fecha TL \\
\hline Cobija-1 & UCTL-840 & Recinto 37 & $555 \pm 50$ & 1440 DC \\
Cobija-1 & UCTL-841 & Recinto 37 & $585 \pm 60$ & 1410 DC \\
Cobija-2 & UCTL-839 & Recinto tambo & $515 \pm 50$ & 1480 DC \\
\hline
\end{tabular}

Tabla 4. Fechados TL para la cerámica de la quebrada de Cobija. 


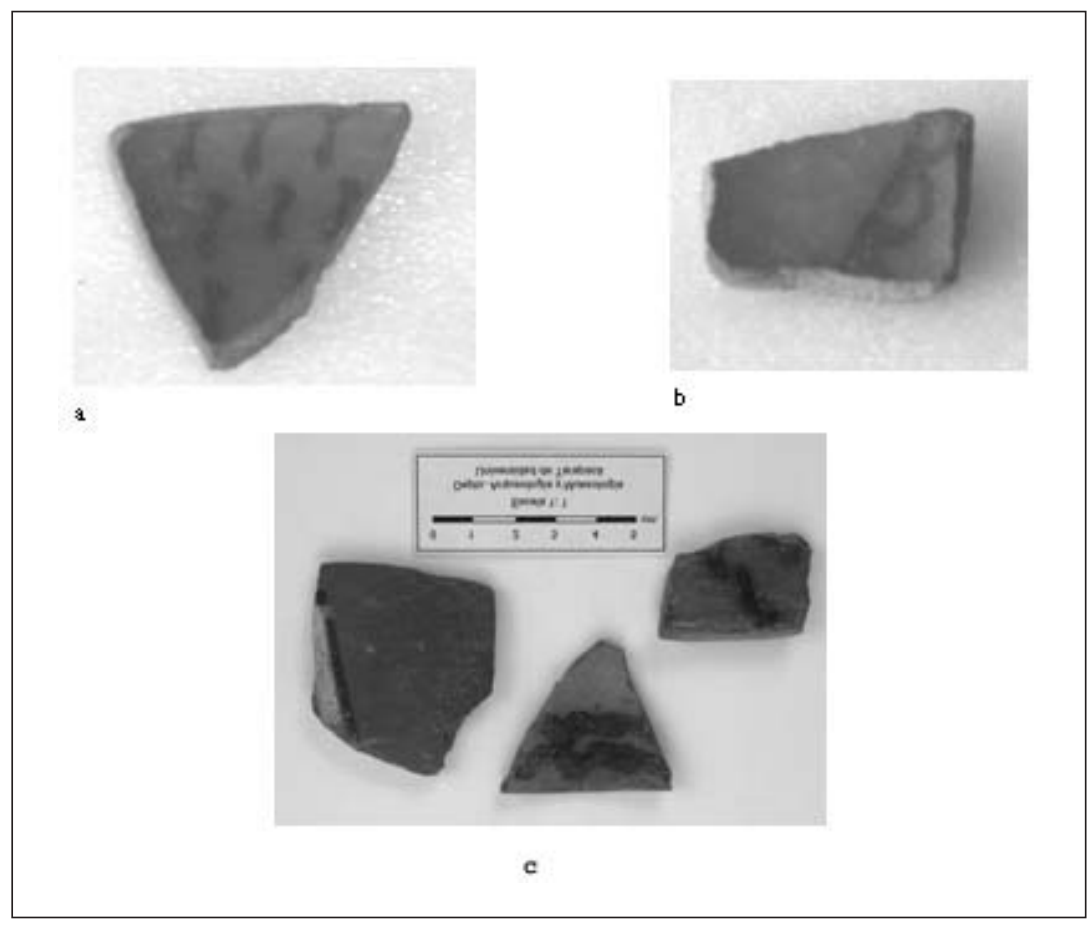

Figura 7. Fragmentos de cerámica: a) estilo Saxamar; b) Negro sobre Rojo; c) Chilpe.

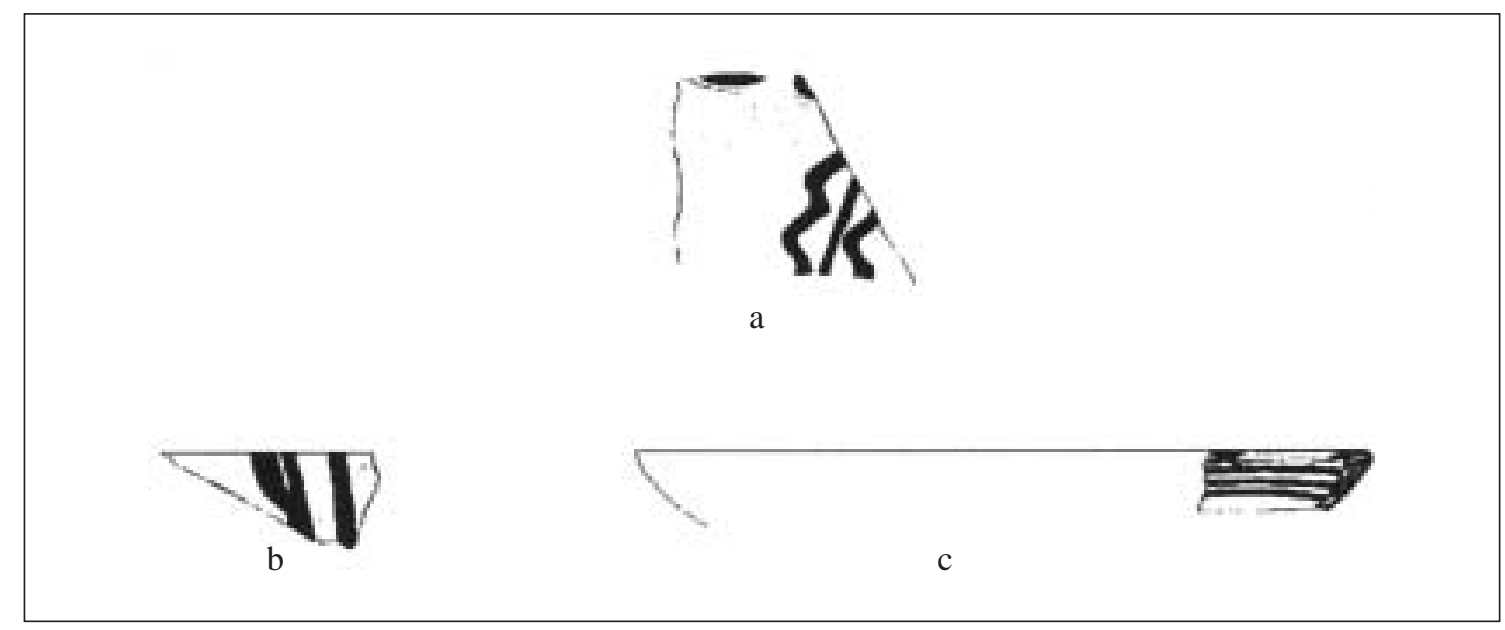

Figura 8. Fragmentos de cerámica fechados: a) Cobija-1, recinto 37 (1440 DC); b) Cobija-1, recinto 37 (1410 DC); c) Cobija-2, recinto tambo (1480 DC).

similar a aquellos de Laco Alto, en Chapiquiña, Vila-Vila en Codpa, y Miñita III en la Quebrada de Miñita (Muñoz et al. 1997). Al igual que en la sierra de Arica, este patrón arquitectónico se repite en el Altiplano Meridional de acuerdo a las descripciones de Escalante (1994) para los Andes bolivianos.
Un aspecto interesante sobre el tema cronológico relacionado con el inca en los Valles Occidentales es lo que planteó Schiappacasse (1999: 139) sobre la base de 80 muestras fechadas por TL y 46 por radiocarbón. Señala que la cronología inca es un problema no resuelto ya que, a pesar que las fechas obtenidas por el método de $\mathrm{C} 14$ son 
compatibles con las hipótesis planteadas por el método histórico, hay fechas que datan contextos de materiales atribuibles al inca, anteriores a 1400 $\mathrm{DC}$, que es cuando se desarrolla el Imperio, por lo cual piensa que no se deben desechar a priori, sino más bien deberían ser consideradas en otras hipótesis alternativas que propongan una mayor antigüedad para la fase imperial y para la cerámica cusqueña y derivados.

\section{El patrón de asentamiento en la quebrada de Cobija}

De acuerdo a su emplazamiento, ambos poblados se edificaron en lugares estratégicos de la quebrada, con un amplio dominio visual. En los dos asentamientos se organizó el espacio en función de áreas definidas cuya ubicación pudo obedecer a varias razones: a) evitar los ambientes malsanos de la quebrada (p.e., evitar las picaduras de insectos); b) resguardo de posibles aluviones o torrenteras, que se producen con frecuencia en época de verano a raíz de los deshielos cordilleranos; c) prevenir amenazas de enfrentamiento por dominios de tierra y agua, al parecer, frecuentes en la sierra de Arica durante el Intermedio Tardío; y d) control de los recursos de agua que alimentaron la quebrada y las tierras agrícolas. El indicador agrario en la quebrada está sustentado por un conjunto de terrazas asociadas a los sitios arqueológicos, en cuyas superficies aparecen restos de cerámica prehispánica. Estas terrazas fueron construidas con muros de contención bajos, de 50 a $60 \mathrm{~cm}$ de altura, y "banquetas" de 4 a $5 \mathrm{~m}$ de ancho. Sin embargo, durante la influencia inca se habría incrementado el número de terrazas y una mayor distribución de canales, abarcando gran parte de la ladera norte.

Respecto a Cobija-1, el asentamiento se planificó en torno a tres áreas bien determinadas. La primera, de tipo residencial, abarcó desde la mitad de ladera hasta la cima de la loma. La segunda, de depósito, se distribuye uniformemente entre el área habitacional y la de corrales y, finalmente, esta última, que se ubica en los faldeos de la loma. Esta planificación fue propia de los asentamientos serranos y puneños durante los períodos Intermedio Tardío y Tardío, es decir, obedecen a un sistema autodefensivo como respuesta a un momento de pugnas interétnicas por intereses productivos. A pesar de esta ubicación estratégica en altura, las áreas que componen este asentamiento, como la agrícola (terrazas) y económica (pozos de almacenajes), mantienen una unidad con el área residencial.

El asentamiento Cobija-2 se presenta, desde el punto de vista espacial, más integrado a las redes de tráfico vinculadas al Qhapaqñan en su tramo Timalchaca-Ticnamar, insertando a la quebrada de Cobija dentro del cordón de la sierra de Huaylillas, espacio fundamental, ya que es el eje que articula la costa con el altiplano. Asociado a este camino, se encuentra un tambo, edificio que debió haber cumplido funciones administrativas del Estado inca, en las que se incluye el almacenamiento de productos. La ubicación de este tambo al igual que otros que hemos estudiado en la sierra de Arica (Zapahuira, Laco Alto, Incahullo, Incauta y Mollegrande; ver Muñoz y colaboradores 1997) fueron construidos en los faldeos de cerros, en los espacios periféricos de los asentamientos, asociados a las áreas económicas como corrales y terrazas de cultivos.

Tanto en Cobija-1 y Cobija-2 hay trazos de caminos prehispánicos que en su momento de mayor tráfico los atravesaron. Estos trazos presentan un ancho promedio de 1 a $2 \mathrm{~m}$. En el caso de Cobija-2 los bordes están empedrados. En las zonas planas de la quebrada estos senderos están constituidos por llanos de tierra y mantienen cierta sinuosidad de acuerdo a la topografía de la quebrada. Su desplazamiento es hacia el valle de Timar, para llegar a la costa, y Timalchaca para desplazarse hacia el altiplano.

\section{El poblamiento humano}

Por la arquitectura y los artefactos de los asentamientos, en este caso la cerámica, vemos que éstos fueron habitados por una población local de la quebrada o valles vecinos. La presencia de grupos foráneos quizás pudo haberse dado en un número menor de individuos vinculados a las poblaciones altiplánicas, las que en el Período Tardío fueron culturalmente influenciadas por los incas. Sin embargo, el poblamiento local pudo haberse organizado como consecuencia de una estructura multiétnica que involucró grupos humanos de la sierra y costa de Arica que se establecieron en la quebrada de Cobija después de la disolución de los vínculos de Tiwanaku. El inter- 
cambio de bienes y productos venidos de distintos ambientes habría ayudado a que se fortalecieran las relaciones sociales y de complementariedad económica, como lo expresa Cúneo Vidal (1978) al señalar que las poblaciones de Caplina y Azapa, al estar relacionadas a los cacicazgos de Chucuito en los siglos XVI y XVII, realizaban periódicos intercambios comerciales.

Las espinas de pescado y restos de fauna malacológica hallados en las excavaciones de Cobija comprobarían los intercambios económicos mantenidos por las poblaciones Cobija con grupos de la costa. En este mismo escenario, también es posible que los grupos de Cobija hayan bajado al Pacífico a pescar o a recolectar productos del mar. Para tal desplazamiento por el desierto costero, los caminos que conectaron la costa con la sierra tuvieron un papel fundamental. De igual manera, se construyeron caminos hacia otras direcciones, lo que permitió conectar poblados tanto de la sierra como del altiplano andino, fortaleciendo lazos económicos (Muñoz y Briones 1996).

Al igual que con la costa, las relaciones entre Cobija y el altiplano pudieron haberse dado en el marco del intercambio, teniendo interés en los recursos pecuarios como los camélidos. Sin embargo, estas relaciones conllevaron posiblemente a que grupos de la puna buscaran espacios en la sierra para asentarse, produciéndose una primera fase de convivencia y tal vez de alianza, especialmente cuando se trató de impulsar el desarrollo agrícola en las cabeceras de valles y sierra. Algunos indicadores que ayudarían a discutir esta hipótesis sería la presencia de una tradición estilística de cerámica Negro sobre Rojo representativa del Altiplano Circumtiticaca y de la Tradición Tardía representada por los estilos Saxamar e Inca. Junto a la presencia de esta cerámica debemos incluir elementos de índole económica como la carne de camélidos y sus derivados.

Con relación al componente social, en la ocupación de ambos asentamientos de Cobija, observamos una variedad de estilos de cerámica de origen serrano y costero; al margen de esta coexistencia alfarera es probable que las poblaciones que manufacturaron esta materialidad hayan, además, interactuado y estructurado el desarrollo en la sie- rra de Arica. Sabemos que a partir del 1200 DC la sierra y las cabeceras de valles de Arica fueron ocupadas sincrónicamente por dos tradiciones culturales, la altiplánica, representada por los estilos alfareros Negro sobre Rojo, y la costera, caracterizada por los estilos San Miguel, Pocoma y Gentilar (ver Uribe 1998, 1999), ambas están estrechamente ligadas al desarrollo agrícola del área y a los sistemas de tráfico que unieron la puna con la costa del Pacífico. Esta coexistencia habría tenido momentos de integración, como se puede observar en los espacios habitacionales, plazas y áreas agrícolas, con cerámica que identifica a ambas tradiciones culturales, y otros momentos de tensión producidos, tal vez, por el uso de los recursos de agua y tierras, lo cual habría llevado a edificar poblados de altura de carácter estratégico.

Sobre la interacción social que se habría producido entre Cobija-1 y Cobija-2 existen tres elementos de discusión. En primer lugar, hay estilos cerámicos, formas y pastas que en alto porcentaje son similares, lo que sugiere que dichas manufacturas pueden haber sido confeccionadas por los mismos artesanos. En segundo lugar, existe una similitud en el patrón arquitectónico habitacional, indicando, al igual que la cerámica, que se manejó la misma idea en torno a planificar y construir los poblados. En tercer lugar, hay un sendero que comunica a ambos asentamientos.

Esta interacción se va a dinamizar aún más con los contactos producidos durante los momentos de influencia inca, cuando poblaciones aymaras incanizadas trajeron alfarería y arquitectura representadas por el estilo Saxamar e Inca Provincial, y por la edificación de tambos y centros ceremoniales, estos últimos como el de Saguara en la quebrada de Camarones (Schiappacasse y Niemeyer 2002).

Desde el punto de vista de la conformación sociopolítica, ambos asentamientos, al parecer, fueron parte de una organización de mayor tipo cacicazgo, cuya cabecera se habría situado en el sector de Belén de la sierra de Arica, lugar donde se concentran los mayores poblados de los períodos prehispánicos tardíos como Huaihuarani, Saxamar y Lupica con una marcada presencia inca a través del centro administrativo de Incahullo (Romero 1999). 


\section{Recursos y población en las quebradas altas de Arica durante la influencia inca}

El Inka en la quebrada de Cobija

En la quebrada de Cobija son escasas las evidencias que permiten sugerir una dominación proveniente del Cusco: no existen construcciones estratégicas como grandes tambos o collca, o un centro administrativo. Cobija-1 y 2 constituyeron, más bien, asentamientos de grupos locales que durante la influencia incaica trabajaron en áreas productivas para el mantenimiento del Estado.

Es probable que la administración incaica en Cobija haya estado relacionada a las poblaciones de habla aymara, como Carangas, y en menor proporción, Pacajes. Esto lo planteamos basándonos en que los estilos de cerámica y arquitectura de los poblados, si bien responden a un patrón local serrano, los estilos de la Tradición Tardía como Saxamar y los de la Tradición Negro sobre Rojo presentan mucha semejanza a los hallados en los territorios de Carangas y Pacajes; incluso el patrón de asentamiento se asemeja a aquellos de la zona de Turco y el Lauca del altiplano boliviano, áreas que están fuertemente relacionadas a ocupaciones Carangas (Heredia 1999). Desde el punto de vista arquitectónico es el tambo el que presenta mayor información para relacionarlo a la arquitectura de estos reinos aymaras; así por ejemplo, el uso de estuco en ambas paredes, compuesto por mortero de tierra y cenizas, el sistema de ángulo recto utilizado para las esquinas de los recintos y el acceso a los recintos de forma trapezoidal con estrecho dintel, constituyen rasgos característicos de la arquitectura Carangas difundida en la quebrada de Cobija.

El interés de los incas, a través de las poblaciones Carangas y Pacajes, por la quebrada de Cobija, al parecer, tuvo su base en el potencial agrícola. La presencia de terrazas y melgas de cultivos aún presentes en los sitios nos obliga a pensar que esta fue la actividad que habría inducido al Inka a interesarse en esta quebrada. Estas poblaciones altiplánicas tal vez ayudaron a desarrollar una economía más dinámica, constituyéndose la mit'a en una estructura que habría ayudado a optimizar la economía local que se sustentaba en la complementariedad e intercambio de productos.
Desde el punto de vista organizativo el sistema de enclaves que se habría adoptado en la sierra de Arica, incluyendo a Cobija durante la influencia incaica, operaría mediante la instalación de algunos mitimaes de origen altiplánico, los cuales habrían estructurado un modo de producción que ayudó a los intereses del Tawantinsuyu. Pensamos que, por las buenas condiciones del agua dulce y del clima, las tierras de la quebrada de Cobija fueron aptas para el cultivo de maíz, yuca, legumbres, ají y calabazas, entre otros productos. En este sentido la construcción del tambo es un indicador de que la producción agrícola de la quebrada fue regulada tanto para la comunidad como para el Estado.

Otro aspecto del interés del Inka por esta quebrada sería la condición de eje articulador en la conexión del área de Codpa con Timalchaca, facilitando o dificultando dicha conexión económica y cultural de acuerdo a sus intereses. Sin embargo, si bien esta conexión se ocupó en momentos previos a la llegada de los incas, su mayor utilización se alcanzó cuando la quebrada de Cobija se integró a las redes de interrelaciones del Tawantinsuyu, pudiendo ser controlada por centros administrativos controlados hegemónicamente, quizás desde Belén o Zapahuira. La presencia inca registrada en otras quebradas serranas de Arica como Cailloma y Laco Alto en Chapiquiña, y Altos de Codpa y Camarones, constituyen claros ejemplos del control espacial que ejercieron los incas sobre la sierra; para tal efecto mejoraron la red vial especialmente en las entradas y salidas de estos asentamientos, construyendo collca y tambos como elementos característicos de su ocupación.

En estos edificios probablemente se guardaron los tributos de la población local que, en el caso de la sierra, pudieron haber sido papas y maíz, y los productos que venían de la costa como el pescado seco, cochayuyo, plumas y prendas, además de los bienes que regalaba el Inka, especialmente tejidos. Cobo (1956 [1653]) y Ondegardo (1990 [1571]) describen estas construcciones como grandes casas de una sola pieza, sin divisiones de aposentos y con dos o tres puertas. Señalan que siguieron siendo utilizados a la llegada de los españoles, y plantean que junto a estos edificios residían en pequeñas chozas o casas levantadas con piedras sin barro los chasqui o indios que oficiaban de correo. 
En el caso de la quebrada de Cobija, la construcción de tambos al parecer no fue determinante para generar un gran cambio en la estructura socioeconómica de la población, sino más bien fue parte de un proceso que no alteró el sistema imperante, es decir, la de una población local de agricultores de origen serrano, la que así como otorgó parte de la producción obtenida al Estado, al parecer recibió aportes de otras áreas tanto de la costa del Pacífico como del Altiplano Circumtiticaca. Este modelo de intercambio se había generado con anterioridad a la llegada de los incas entre las poblaciones de la sierra y valles de Arica y las poblaciones altiplánicas, entre ellas Carangas y Pacajes.

\section{EI Inka en la serranía de Arica}

La influencia del Tawantinsuyu en la sierra se caracteriza por un patrón arquitectónico de recintos rectangulares dispuestos en hilera y adosados. Este tipo de construcciones marca una diferencia significativa con aquellas circulares u ovales, características de las sociedades locales del Intermedio Tardío. Esta arquitectura utilizada para la construcción de tambos se encuentra asociada a estilos de cerámica Saxamar, Inca cusqueña, engobes rojos bruñidos, semejantes al estilo Sillustani e Inca Altiplánico. Estos materiales se registran en asentamientos que contaron con un gran potencial agrícola y recursos permanentes de agua, y que fueron ocupados originalmente por poblaciones locales.

Algunas instalaciones incaicas estudiadas corresponden a los tambos de Zapahuira-1 y 2, emplazados cerca de campos de cultivos. Se trata de dos conjuntos rectangulares distantes uno de otro por casi $200 \mathrm{~m}$. Zapahuira-1 fue un depósito o collca destinado al almacenamiento de productos agrícolas, tal como lo evidencia su estructura de construcción que contempla drenajes subterráneos y un complejo sistema de piso inicial compuesto por sucesivas capas de grava. Tales características señalan una particular preocupación que, a nuestro juicio, está destinada a la preservación de los bienes almacenados (Muñoz et al. 1987a, 1987b).

En Belén, el sitio Incahullo es otra evidencia arquitectónica de la época inca. Comparte el área con los poblados de Ancopachane, Trigalpampa, Chajpa y Huaihuarani, pero su construcción fue hecha separadamente de estos asentamientos.
Incahullo como Zapahuira-2, presenta recintos preferentemente rectangulares. Los muros están trabajados en sus esquinas y tienen señas de revoque y pintura roja. Es probable que algunos de los recintos que conforman estos asentamientos correspondieran a depósitos.

En Codpa uno de los asentamientos con mayor vinculación al Tawantinsuyu es el tambo de Incauta, cuyas instalaciones conformadas por tres recintos rectangulares se situaron en un extremo del poblado inmediatamente bajo el sector denominado "plaza". En él se registró mayoritariamente cerámica Inca cusqueña y Saxamar (Muñoz et al. 1987a, 1987b). Otro ejemplo de construcción de tambo lo constituye el sitio Molle Grande-2, ubicado en las faldas del cerro homónimo. Está conformado por nueve recintos rectangulares distribuidos en hilera, en los cuales se registró cerámica inca de imitación cusqueña.

La edificación de las estructuras de tambos asociados a cerámica Inca cusqueña y Saxamar nos sugiere que la presencia incaica en las tierras altas de Arica tuvo un carácter administrativo, controlando la producción agrícola. Este control se habría establecido a lo largo de la sierra y cabeceras de valles, especialmente donde se establecieron los asentamientos de agricultores, mejorando la red vial que comunicaba a estos pueblos con el fin, tal vez, de que el control fuese más expedito e intenso. Al norte de Zapahuira, en el área de Socoroma, las investigaciones realizadas por Santoro y colaboradores (1987) presentan evidencias del camino incaico con tramos que fueron emplantillados en piedra. Por su parte, al sur de Codpa, Niemeyer y colaboradores (19721973) han documentado la continuidad de la red vial y la presencia de otras instalaciones incaicas en Sahuara y Pachica. En el oasis más meridional de la zona arqueológica de Arica, Miñita, también es posible reconocer la presencia incaica a través de la bien elaborada alfarería Saxamar, entierros en chullpa y silos para el almacenaje de la producción agrícola (Muñoz y Santos 1998).

El análisis de los materiales que hemos presentado nos lleva a plantear que, para comprender la naturaleza de la influencia incaica en la zona, hay que remontarse al rol que jugaron las poblaciones preincaicas que habitaban estos territorios. El conocimiento adquirido en las distintas actividades en que se especializaron, como la pesca, agricul- 
tura y ganadería, constituyó el mayor interés de parte del Inka, quien habría aprovechado este conocimiento que las poblaciones locales tenían del medio, mejorando algunos componentes tecnológicos como las redes viales, lo que hizo que las comunicaciones fueran más fluidas, permitiendo la llegada de objetos y bienes novedosos, y mayores recursos económicos y tecnológicos. Sin embargo, la llegada de nuevas ideas en términos de readecuar la producción y la modificación de algunas tecnologías en el trabajo agrario no alteró la estructura económica que identificó a las poblaciones locales.

En este contexto, pensamos más bien que los representantes del Tawantinsuyu se integraron al proceso económico de la región sin producir grandes cambios, incluso los patrones funerarios más representativos como las chullpa no fueron alteradas y se siguieron ofrendando, lo que demuestra un concepto más integrador que destructivo en esta región cultural. Pensamos que el dominio fue más selectivo que marginal ya que toda el área quedó interconectada al sistema vial. Esta situación continúa hasta la llegada de los europeos, quienes, al igual que los incas, siguieron aprovechando la experiencia local asentándose igualmente en los mejores espacios productivos, de donde comenzarán a ejercer las primeras estrategias de dominio.

\section{Consideraciones finales}

El estudio de los asentamientos en la quebrada de Cobija sugiere que las poblaciones asentadas en estos poblados fueron agricultores que se apoyaron en términos de subsistencia en la ganadería de camélidos. La red de caminos y material orgánico encontrado en las basuras indican que estos grupos se vincularon con espacios costeros y puneños, constituyéndose estas quebradas serranas en una bisagra que conectaba a los pastores altoandinos con los pescadores del litoral del Pacífico.

La composición social de la gente que habitó los asentamientos de Cobija-1 y Cobija-2, al parecer, fue parte de pequeños cacicazgos conformados por grupos de familias serranas, cuya actividad central fue la agricultura. La existencia de estos cacicazgos habría ayudado a fortalecer un tráfico económico que alcanzó distintos pisos ecológicos, lo que se evidencia en las redes viales que comu- nicaban diversos poblados y aldeas construidas en laderas y cimas de cerros, mostrando a su vez una compleja planificación de los poblados dentro de una red social que se constituyó a partir del Intermedio Tardío.

Estos cacicazgos en la sierra de Arica entre el 1100 a 1450 DC, al parecer, se organizaron a través de unidades independientes construyendo pucaras y aldeas en lugares estratégicos, algo similar a lo que postuló Hyslop (1992) para los reinos altiplánicos de la puna. Sin embargo, entre 1450 a 1550 DC con la influencia inca en estas tierras, si bien continuaron siendo gobernadas por los caciques locales, se edifican tambos y se mejora la red vial, principalmente la que cruza la sierra, tal vez como una forma de comunicar e integrar a todos los pueblos al sistema económico y social del Tawantinsuyu. La llegada de los incas, al parecer, fue un proceso gradual facilitado por las poblaciones altiplánicas (Carangas) cuyo dominio de las tierras cultivables en los valles costeros del norte de Chile se había desarrollado a partir de 1300 DC.

Si bien es cierto, aún falta por conocer el comportamiento bioantropológico, genético y paleopatológico de las poblaciones serranas -entre ellas las de la quebrada de Cobija- que interactuaron en el Período Tardío, resulta claro que, por la variedad de estilos cerámicos, la sierra y cabeceras de valles del extremo norte de Chile fueron ocupados de manera pluriétnica, lo que determinó una constante interacción social que se tradujo en acciones armónicas y de conflicto; quizás esta última situación fue consecuencia del control de los recursos hídricos y tierras cultivables. En este escenario es cuando ocurre la llegada de los incas, que al margen de aportar algunos cambios estructurales en la economía, la estructura social de los agricultores de los altos de Arica no sufrió transformaciones, como sí ocurrió en otras áreas de los Andes.

Agradecimientos Este artículo es resultado del Proyecto 3740-00, financiado por la DIPOG, Universidad de Tarapacá, y del Proyecto FONDECYT 1040296. Se agradece a la especialista Mariela Santos por haber realizado la descripción del material cerámico de los sitios Cobija-1 y Cobija-2, y a la profesora Eugenia Rosello por la revisión del texto. 


\section{REFERENCIAS CITADAS}

ALVAREZ, L., 1991. Etnopercepción andina del espacio, valles dulces y valles salados, en la vertiente occidental de los Andes. Diálogo Andino 10: 9-20.

CAVAGNARO, L., 1986. Materiales para la historia de Tacna. Tomo II, Dominación hispánica. Editorial Cooperativa San Pedro, Tacna.

COBO, B., 1956 [1653]. Historia del Nuevo Mundo. Biblioteca de Autores Españoles, Ediciones Atlas, Madrid.

CUNEO VIDAL, R., 1978. Historia de los cacicazgos del sur del Perú. En Obras completas, I. Prado Pastor (Ed.), vol. 1: 295-489. Editorial Gráfica Morsom, Madrid.

DAUELSBERG, P., 1961. Algunos problemas sobre la cerámica de Arica. Boletín del Museo Regional de Arica 5: 94-108.

D'AlTROY, T., 1992. Provincial power in the Inca Empire. Smithsonian Institution Press, Washington, Londres.

D'ALTROY, T. y D. BISHOP, 1990. The provincial organization of inca ceramic production. American Antiquity 55 (1): 120-138.

DIEZ DE SAN MIGUEL, G., 1964 [1567]. Visita hecha a la provincia de Chucuito por Garci Diez de San Miguel en el año de 1567. Casa de la Cultura del Perú, Lima.

ESCALANTE, J., 1994. Arquitectura prehispánica en los Andes bolivianos. Impreso en CIMA, La Paz.

ESPOUEYS, O., V. SCHIAPPACASSE, M. URIBE y J. BERENGUER, 1995. En torno al surgimiento de la cultura Arica. Actas del XIII Congreso Nacional de Arqueología Chilena, pp. 171-184. Antofagasta.

GORDILLO, J., 1996. Desarrollo Regional Tardío y ocupación inca en la precordillera de Tacna. Ciencia y Desarrollo 3: 96-111.

GORDILLO. J. y M. GARCIA, 1989. Arquitectura funeraria y análisis contextual de algunas tumbas de Peañas: Breve comentario. Mallku 1: 2-28.

HEREDIA, M., 1999. Las torres funerarias de Culli Culli, Bolivia. Un sitio del Período Tardío del Area Centro Sur Andina. Tesis para optar al Título de Licenciado en Arqueología. Escuela Nacional de Arqueología e Historia. I.N.A.H. México D. F.

HIDALGO, J., 1996. Relaciones protohistóricas interétnicas de las poblaciones locales y altiplánicas de Arica. La integración surandina: Cinco siglos después, X. Albó, M. I. Arratia, J. Hidalgo, L. Núñez, A. Llagostera, I. Remy y B. Revesz (Eds.), pp. 161-174. Estudios y Debates Regionales Andinos, Cusco.

HIDALGO, J. y G. FOCACCI, 1986. Multietnicidad en Arica, siglo XVI, evidencias etnohistóricas y arqueológicas. Chungara 16/17: 137-148.
HYSLOP, J., 1992. Qhapaqñan. El sistema vial incaico. Instituto Andino de Estudios Arqueológicos, Lima.

JULIEN, C., 1983. Guano and maize agriculture in $16^{\text {th }}$ century in Arequipa. En An interdisciplinary perspective on Andean complementary, S. Mazuda, I. Shimada y C. Morris (Eds.), pp. 185-213. Simposium 91, Wenner-Green Foundation, Florida.

LLAGOSTERA, A., 1976. Hipótesis sobre la expansión incaica en la vertiente occidental de los Andes Meridionales. Homenaje R. P. Gustavo Le Paige, L. Núñez (Ed.), pp.203-218. Universidad del Norte, Antofagasta.

MORRIS, C., 1981. Tecnología y organización inca del almacenamiento de víveres en la sierra. En La tecnología del mundo andino, H. Lechtman y A. M. Soldi (Eds.), T I: 327-375. Instituto de Investigaciones Antropológicas de la Universidad Nacional Autónoma de México. Serie Antropología 36. Arqueología, México D. F.

MULVANY, E., 2003. Control estatal y economías regionales. Cuadernos 20: 173-197.

MUÑOZ, I., 1989. Perfil de la organización económica social en la desembocadura del río Camarones. Período Intermedio Tardío e Inca. Chungara 22: 85-112.

-1996. Asentamientos e interrelaciones culturales: Una aproximación al proceso prehispánico tardío en la sierra de Arica. Tawantinsuyu 2: 44-58.

1998. La expansión incaica y su vinculación con las poblaciones de los Valles Occidentales del extremo norte de Chile. Tawantinsuyu 4: 127-138.

MUÑOZ, I. y L. BRIONES, 1996. Poblados, rutas y arte rupestre precolombinos de Arica: Descripción y análisis de sistema de organización. Chungara 28 (1-2): 47-84.

MUÑOZ, I. y J. CHACAMA, 1988. Cronología por termoluminiscencia para los períodos Intermedio Tardío y Tardío en la sierra de Arica. Chungara 20: 19-45.

1993. El Inka en la sierra de Arica. Actas del XII Congreso Nacional de Arqueología Chilena, T I: 269-284. Temuco.

-1995. Uso del espacio y relaciones interculturales en la sierra de Arica: El caso de las sociedades prehispánicas del Período Intermedio Tardío. Actas del Segundo Congreso Chileno de Antropología, T II: 591-597. Santiago.

MUÑOZ, I. y M. SANTOS, 1998. Desde el Período Tiwanaku al Indígena Colonial: Uso del espacio e interacción social en la quebrada de Miñita, norte de Chile. Diálogo Andino 17: 69-114.

MUÑOZ, I., J. CHACAMA, G. ESPINOSA y L. BRIONES, 1987a. La ocupación prehispánica tardía en Zapahuira y su vinculación a la organización social y económica inca. Chungara 18: 67-90.

MUÑOZ, I., J. CHACAMA y G. ESPINOSA, 1987b. El poblamiento prehispánico tardío en el valle de Codpa. 
Una aproximación a la historia regional. Chungara 19: 7-70.

MUÑOZ, I., J. CHACAMA y M. SANTOS, 1997. Tambos, pucaras y aldeas, evidencias del poblamiento humano y de contacto indígena-europeo en el extremo norte de Chile: Análisis de los patrones habitacionales y nuevas dataciones radiométricas. Diálogo Andino 16: 123-190.

MURRA, J., 1975. El control vertical de un máximo de pisos ecológicos en la economía de las sociedades andinas. En Formaciones económicas y políticas del mundo andino, pp. 59-116. Instituto de Estudios Peruanos, Lima.

NIEMEYER, H., SCHIAPPACASSE, V. y I. SOLIMANO, 1972-73. Padrones de poblamiento de la quebrada de Camarones (prov. de Tarapacá). Actas del VI Congreso de Arqueología Chilena, pp. 115-138. Santiago.

ONDEGARDO, P., 1990 [1571]. El mundo de los incas, L. González y A. Alonso (Eds.). Crónicas de América 58. Historia 16. Madrid.

PARSSINEN, M., 1992. Tawantinsuyu. The Inca State and its political organization. Studia Historica 43. SHS, Helsinki.

QUEREJAZU, R., 1989. Bolivia prehispánica. Librería y Editorial Juventud, La Paz.

RAFFINO, R., 1996. La integración surandina en tiempos del Tawantinsuyu. La integración surandina cinco siglos después, X. Albó, M. I. Arratia, J. Hidalgo, L. Núñez, A. Llagostera, M. I. Remy y B. Revesz (Comps.), pp. 63-80. Estudios y Debates Regionales Andinos 91, Cusco.

RICE, P., 1987. Pottery analysis. A sourcebook. University of Chicago, Chicago.

RICE, D., G. CONRAD y L. WATANABE., 1990. Proyecto Osmore: Un estudio del Programa Contisuyu sobre la complementariedad económica en la prehistoria tardía de la cuenca del Osmore, Moquegua, Perú. Trabajos Arqueológicos en Moquegua, Perú, vol. 3: 7-38. Lima.

RIVERA, M., 2002. Historias del desierto: Arqueología del norte de Chile. Editorial del Norte, La Serena.

ROMERO, A., 1999. Ocupación multiétnica en la sierra de Arica: Arquitectura, uso del espacio y distribución cerámica en el poblado arqueológico de Huaihuarani. Boletín Zeta www.masma.uta.cl

ROSTWOROWSKI, M., 1986. La región del Colesuyo. Chungara 16-17: 127-136.
RYDEN, S., 1947. Archaeological researches in the highlands of Bolivia. Erlanders Boktryckeri Aktiebolag, Gotenburgo.

SANTORO, C., 1995. Late prehistoric regional interaction and social change in a coastal valley of Northern Chile. Doctoral Dissertation, University of Pittsburgh, Pittsburgh.

SANTORO, C. y I. MUÑOZ, 1981. Patrón habitacional incaico en el área de Pampa Alto Ramírez. Chungara 7: 144-171.

SANTORO, C., J. HIDALGO y A. OSORIO, 1987. El Estado inca y los grupos étnicos en el sistema de riego de Socoroma. Chungara 19: 71-92.

SANTOS, M., A. ROMERO y C. SANTORO, 1996 Ms. Propuesta tipológica de estándares de pasta para la cerámica post-Tiwanaku en los Valles Occidentales. Anexo de Informe Final Proyecto FONDECYT 1950961, Santiago.

SCHIAPPACASSE, V., 1999. Cronología del Estado inca. Estudios Atacameños 18: 133:140.

SCHIAPPACASSE, V. y H. NIEMEYER, 2002. Ceremonial inca provincial: El asentamiento de Saguara (Cuenca de Camarones). Chungara 34 (1): 53-84.

SCHIAPPACASSE, V., V. CASTRO y H. NIEMEYER, 1989. Los Desarrollos Regionales en el Norte Grande (10001400 DC). En Prehistoria de Chile. Desde sus orígenes hasta los albores de la Conquista, J. Hidalgo, V. Schiappacasse, H. Niemeyer, C. Aldunate e I. Solimano (Eds.), pp. 181-220. Editorial Andrés Bello, Santiago.

SILVA, O., 1992-1993. Reflexiones acerca del dominio incaico en Tarapacá (Chile). Diálogo Andino 11-12: 77-94.

STANISH, C., 1990. Complementariedad zonal en Moquegua: Una aproximación desde el valle de Otora. Arqueología de los Valles Occidentales del Area Centro Sur Andina. Gaceta Arqueológica Andina 5 (18-19): 137-158.

TRIMBORN, H., 1973. Investigaciones arqueológicas en el Departamento de Tacna (Perú). Atti del XL Congreso Internazionale Degli Americanisti (1972), T I: 333-335. Génova.

URIBE, M., 1998. Cerámicas arqueológicas de Arica: II etapa de una revaluación tipológica (períodos Intermedio Tardío y Tardío). Contribución Arqueológica 5, T II: 13-44.

-1999. La cerámica de Arica 40 años después de Dauelsberg. Chungara 31 (2): 189-228.

WILliams, V. y T. D’ALTROY, 1998. Al sur del Tawantinsuyu: Un dominio selectivamente intensivo. Tawantinsuyu 5: 170-178. 